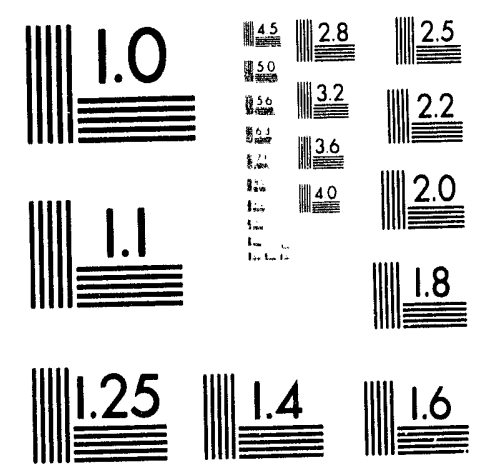



$1=0$

$1:$

NOY 191993
OSTI
UCRL-ID 112776

Reprinted from Engineering Research, Development, and Technology.

Thrust Area Report FY 92

UCRL 53868-92

\title{
Microwave and Pulsed Power
}

\author{
E. Karl Freytag
}

March, 1993

This is an informal report intended primarily for internal or limited external distribution. The opinions and conclusions stated are those of the author and may or may not be those of the Laboratory. Work performed under the auspices of the U.S. Department of Energy by the Lawrence Livermore National Laboratory under Contract W-7405-Eng-48. 
This document was prepared as an account of work sponsored by an agency of the United States Government. Neither the United States Government nor the University of California nor any of their employees, makes any warranty, express or implied, or assumes any legal liability or responsibility for the accuracy, completeness, or usefulness of any information, apparatus, product, or process disclosed, or represents that its use would not infringe privately owned rights. Reference herein to any specific commercial products, process, or service by trade name, trademark, manufacturer, or otherwise, does not necessarily constitute or imply its endorsement, recommendation, or favoring by the United States Government or the University of California. The views and opinions of authors expressed herein do not necessarily state or reflect those of the United States Government or the University of California and shall not be used for advertising or product endorsement purposes.

This report has been reproduced directly from the best available copy.

Available to DOE and DOE contractors from the

Office of Scientific and Technical Information P.O. Box 62, Oak Ridge, TN 37831

Prices available from (615) 576-8401, FTS 626-8401

Available to the public from the

National Technical Information Service

U.S. Department of Commerce 5285 Port Royal Rd.

Springfield, VA 22161 


\section{Microwave and Pulsed Power}

E. Karl Freytag 


\section{Microwave and Pulsed Power}

The goals of the Microwave and Pulsed Power thrust area are to identify realizable research and development efforts and to conduct high-quality research in those pulse power and microwave technologies that support existing and emerging programmatic requirements at Lawrence

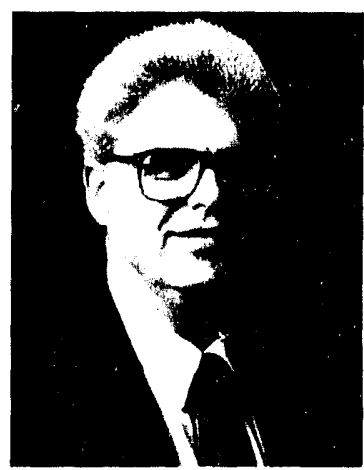
Livermore National Laboratory (LLNL). Our main objective is to work on nationally important problems while enhancing our basic understanding of enabling technologies such as component design and testing, compact systems packaging, exploratory physics experiments, and advanced systems integration and performance. During FY-92, we concentrated our research efforts on the six project areas described in this report.

1. We are investigating the superior electronic and thermal properties of diamond that may make it an ideal material for a high-power, solidstate switch.
2. We are studying the feasibility of using advanced Ground Penetrating Imaging Radar technology for reliable non-destructive evaluation of bridges and other high-value concrete structures. These studies include conceptual designs, modeling, experimental verifications, and image reconstruction of simulated radar data.

3. We are exploring the efficiency of pulsed plasma processing techniques used for the removal of NOx from various effluent sources.

4. We have finished the investigation of the properties of a magnetically delayed low-pressure gas switch, which was designed here at LLNL.

5. We are applying statistical electromagnetic theory techniques to help assess microwave effects on electronic subsystems, by using a mode stirred chamber as our measurement tool.

6. We are investigating the generation of perfluoroisobutylene ([FIB) in propesed CFC replacement fluids when they are subjected to high electrical stresse's and breakdown environments.

E. Karl Freytag Thrust Areu Le'tuder 
Section 7

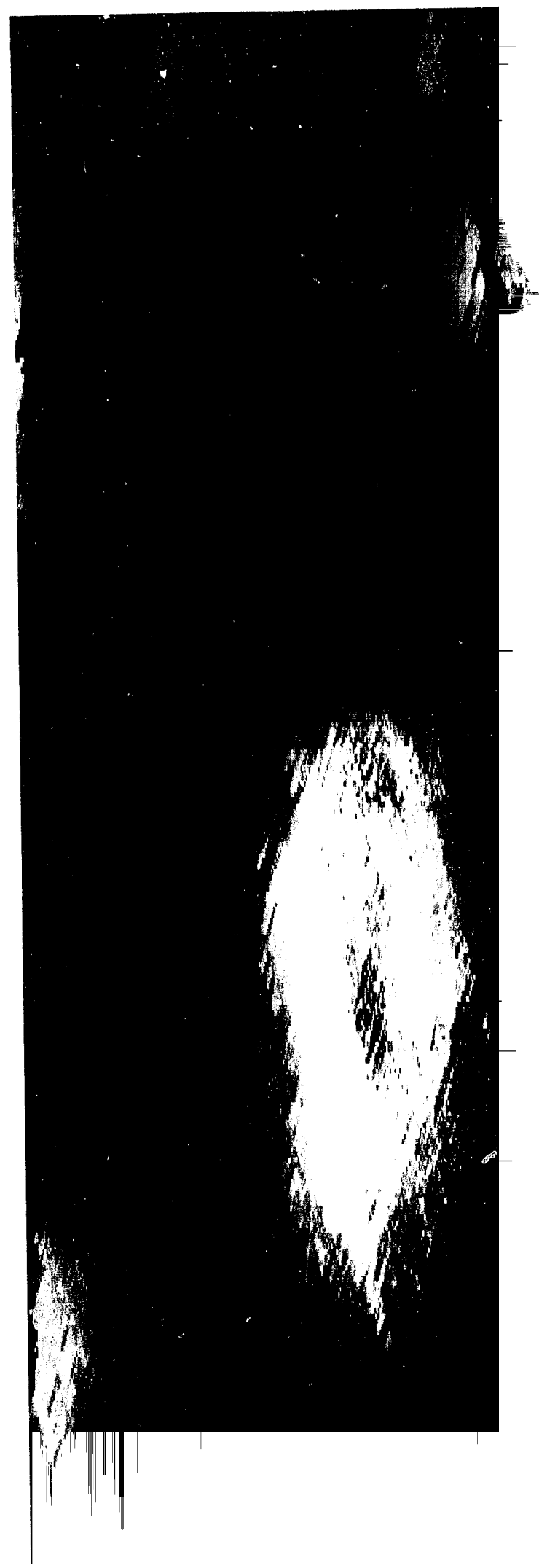




\section{Microwave and Pulsed Power}

\section{Overview}

E. Karl Freyrag, Throtist Area Leader

Pulsed Plasma Processing of Effluent Pollutants and Toxic Chemicals

George E. Vogtlin

Ground Penetrating Imaging Radar for Bridge Inspection

Jolnn P. Warluns, Scott D. Nelson, Jose M. Hernandez,

Erik M. Johansson, Hua Le', and Brett Douglass

High-Average-Power, Electron Beam-Controlled Switching in Diamond

W. Wayne Hofer, Don R. Kania, Karl H. Schoenbach,

Ravindra Joshi, and Ralf P. Brinkmanm

Testing of CFC Replacement Fluids for Arc-Induced Toxic

By-Products

W. Ray Cravey, Wayne R. Luedtka, Ruth A. Hawoley-Fedder, and

Linda Foiles

Applying Statistical Electromagnetic Theory to Mode Stirred Chamber Measurements

Richard A. Zacharias and Carlos A. Avalle

Magnetically Delayed Low-Pressure Gas Discharge Switching

Stephen E. Sampayan, Hugh C. Kirbic', Anthony N. Pannc',

Eugene Laner, and Donald Prosnitz 


\title{
Pulsed Plasma Processing of Effiuent Pollutants and Toxic Chemicals
}

\author{
George E. Vogtlin \\ Defense Sciences Engineering Division \\ Electronics Engineering
}

We are exploring the efficiency of pulsed plasma processing in the removal of $\mathrm{NO}_{x}$ and other pollutants. Our ultimate goal is a flow-through system where gases would be treated during a single pass. We are currently using a closed-loop system with mixtures of bottled gas. The closed-loop system permits testing of processes, without a requirement for the development of complex and expensive power supplies for the one-pass treatment. We have constructed a new processor this year that can accommodate many electrode shapes at temperatures up to $400^{\circ} \mathrm{F}$.

\section{Introduction}

The efficient removal of $\mathrm{NO}_{\mathrm{x}}$ from effluent sources is essential to meet the requirements of the Clean Air Act. $\mathrm{NO}_{\mathrm{x}}$ is a mixture of nitric oxide, $\mathrm{NO}$, and nitrogen dioxide, $\mathrm{NO}_{2}$. We are exploring the efficiency of pulsed plasma processing in the removal of $\mathrm{NO}_{x}$ and other pollutants. Pulsed plasma appropriate for processing is generated by a short high-voltage pulse between two electrodes. The electrons from this discharge create radicals from the air molecules. These radicals can then react with the pollutants to give harmless or removable substances.

Our ultimate goal is a flow-through system where gases would be treated during a single pass. We are currently using a closed-loop system with mixtures of bottled gas. The closed-loop system permits testing of processes, without a requirement for the development of complex and expensive power supplies for the one-pass treatment. We also believe that flow through the reactor should be in turbulent flow. Turbulent flow means that all the gases in the processor flow through at the same velocity, including that at the wall. The closedloop system permits these high flow rates without an extensive gas-mixing and heating system.

\section{Progress}

\section{Experimental System}

The experimental system permits the introduction of various gas combinations prior to testing.
Analysis can be conducted during or after these tests. We have constructed a new processor this year that can accommodate many electrode shapes at temperatures up to $400^{\circ} \mathrm{F}$. This processor is shown in Fig. 1.

Electrode geometries can have a cricial role in the efficiency of this process. It is essential to efficiently couple the energy uniformly into the gas. The geometry can affect the power supply coupling efficiency, the discharge uniform ty, and the pressure losses due to turbulence.

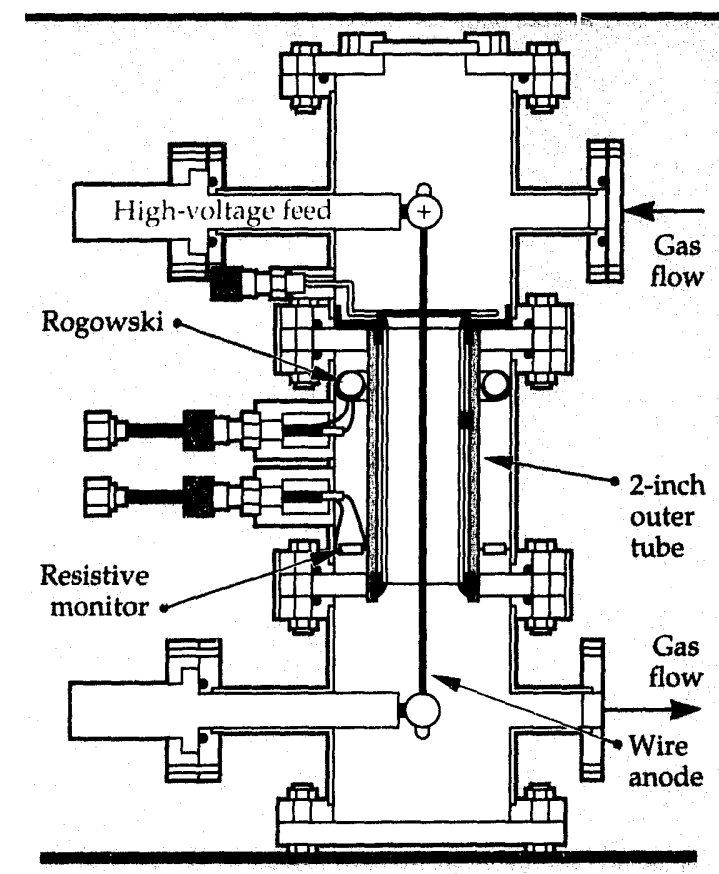

Figure 1. Processor for removing effiuent pollutants. 
Figure 2.

Electrode geometry for processor.

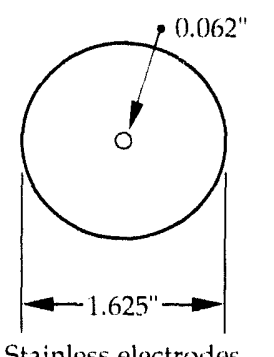

Stainless electrodes

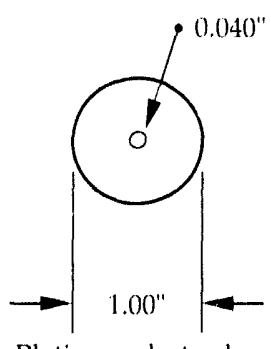

Platinum electrodes

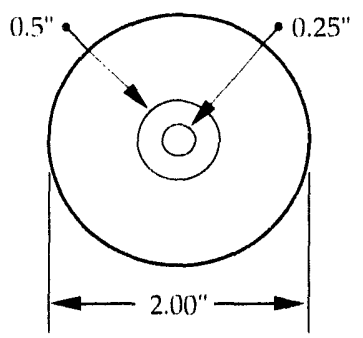

Brass discs $0.005^{\prime \prime}$ thick $0.25^{\prime \prime}$ separation

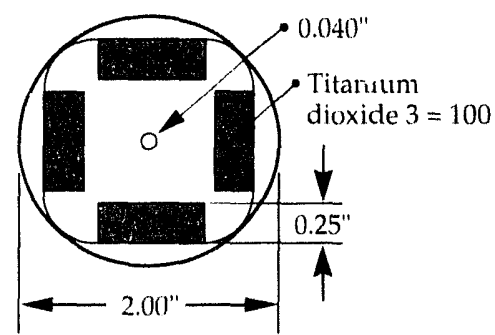

Platinum wire $0.0400^{\prime \prime}$

Titanium oxide plates Stainless outer tube
The precessing chamberhasbeendesigned with ancuterpipe two inches in diameter. This tubecon be used as an electrode; other geometries of smallor dimensions can be place inside. The reaction chamber com be increased in length as needed to match the impedance of the high voltage feed to that of the processer, for maximum energy transfer. Configurations tested for No removal are shown in Fig. 2.

\section{Nitric Oxide Removal}

We messure the efficiency of remoxal in eV/ molecule. The performance of the remoxis in ex/ No molecule is a function of the $\mathrm{NO}$ (oncentration. We are presently charging the system to approximately ox pene (parts per million by volume $\mathrm{NO}$ ) reats with itself in the presence of air, and the change in concentration is propertional to the square of the concentration. This means that the natural rate of $\mathrm{N}()$ reafuction at $5(1)$ ppms is 25 times that at $10(1)$ ppms. This effect must be subtracted from the reduction due to pulse plasma processing. The natural reduction of $\mathrm{NO}$ has a
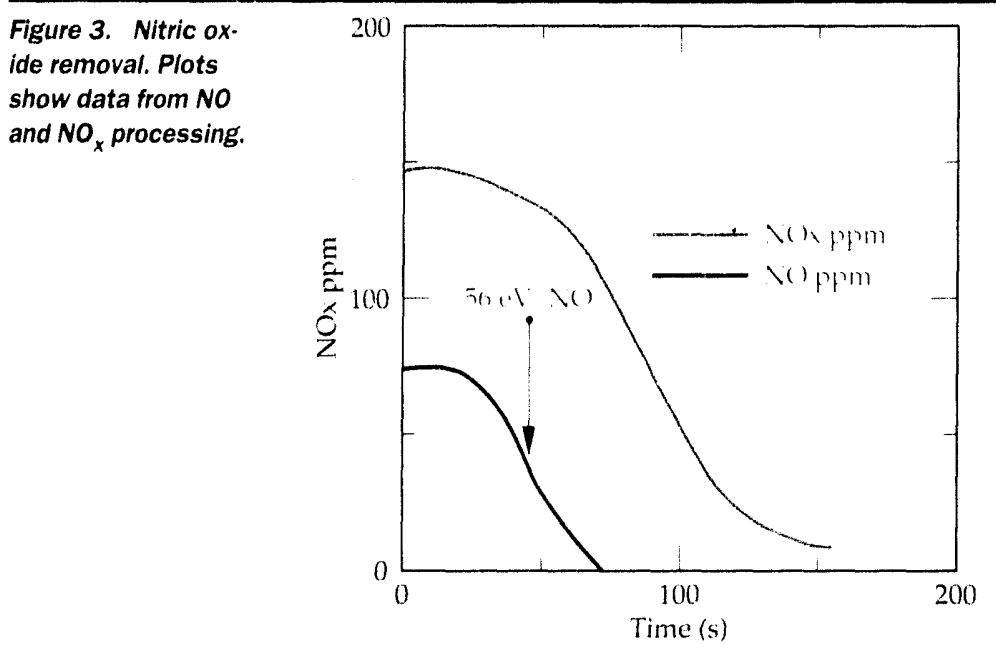

negative temperature cerefficient, which means the reduction is less at higher temperatures. At room temperature, the natural decay at 50() ppms is approximately equivalent to 2(l-pulses-per-second pulse plasma processing. We feel the present system gives grod data to the 50) ppme level and can go to higher ppme at higher temperatures. The efficiency of NO remosal has shown to be sensitive to concentration. Figure 3 show's this effect. It apperses that the remoxal of $\mathrm{NO})_{2}$ increases once the No has been remored.

Initial measurements will be made with the closed-loop system; however, we intend to conrert this system to a flow-through system, which will permit steady-state mixing.

\section{Additives: N-octane and Water}

The addition of n-extane has improved the efficiency of $\mathrm{VO}$ ) remowal. Figure 4 shows eifficiency improsements with 11,1850 ppms of n-octane. N-xitane is similar te gasoline and has a flammeability limit of $8(x)$ ppms at room temperature. The addition of n-octane, suggested by R. Atkinson,! uses a process that effectively bums organics by recycling the OH radical. This process should be possible with many organic oompounds. It seems likely that the work by Fujii,- using an oil that is raperized in the processing chamber, is a similar process.

Tests to date have been with dry air and with approximately one percent water. The tests with dre air have an efficiency similar to wet air. We plan tests in the near future with water up to eight percent by solume at 2 () 1 \%:

\section{Diagnostics}

Diagnostic systems have been used to analye the light emissioms of the discharge. These include a monochrometer and an open shutter camera. Deviees to measure the results of chemical reac- 


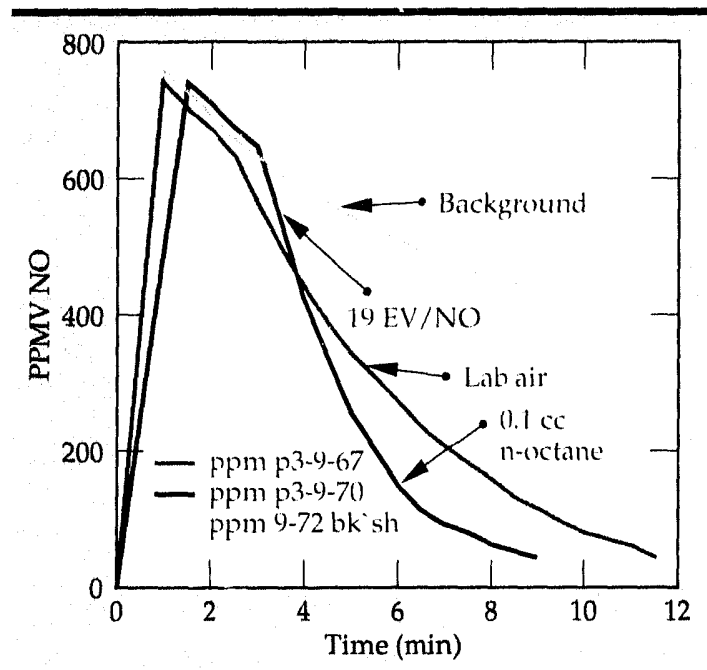

Figure 4. Results from noctane addition in NO removal.

tions include a chemical $\mathrm{NO}_{\mathbf{x}}$ meter, a chemiluminescence $\mathrm{NO}_{x}$ meter, and an IR and FTIR analyzer.

The measurement of energy is essential to determine the efficiency. We measure the energy by recording the voltage and current as a function of time, and then integrate the product. This gives us the joules per pulse. The pulse rate is measured by a counter. The total energy in any time period is then the product of the time pulse rate and joules per pulse. To prevent reflections, a load resistor is included at the end of a short transmission line, where the voltage is measured with a voltage divider. The current is measured with a $0.1-\Omega$ resistor in the return path.

\section{Applications}

Diesel Application. The application of this technology to diesel exhaust cleanup poses many challenges due to weight, size, life, cost, and efficiency requirements. We are developing power supplies with similar requirements as part of the Laser Isotope Separation Program at Lawrence Livermore National Laboratory. It may be possible to meet these requirements if the efficiency of $\mathrm{NO}_{x}$ removal is sufficiently improved. Our goal would be to remove the required $\mathrm{NO}_{\mathrm{x}}$ with less than two percent of the engine power output. This would require 8 hp or $6 \mathrm{~kW}$ for a 400 hp engine.

The efficiency of the overall process is the key to diesel applications. The higher the efficiency, the more likely this process will be practical. It may be that the electrical energy can be generated by thermal-electric generators that use the engine waste heat. These devices would require no loss in engine power to clean the exhaust.

Other pollutants may be removed or destroyed by this plasma process. It is likely that fuel droplets, carbon monoxide, and volatile organic hydrocarbons may be oxidized to harmless compounds. It may also be possible to remove particulates using this process in the presence of liquid droplets.

Coal-Fired Power Plants. This technology can be applied to coal-fired power plants. It may be possible to simultaneously remove $\mathrm{NO}_{x}, \mathrm{SO}_{x}$, mercury, and particulates from the effluent. The removal of both $\mathrm{NO}_{2}$ and $\mathrm{SO}_{x}$ would be accomplished by their reaction with ammonia. This reaction gives ammonium sulfate and nitrate, which can be sold as fertilizer.

The critical issue in this appiication is cost. It must be competitive with other processes. Improvement of efficiency results in reduced capital costs and operating costs. Our primary goal is improvement of the efficiency of simultaneous removal of $\mathrm{NO}_{\mathrm{x}}$ and $\mathrm{SO}_{\mathrm{x}}$.

Other Applications. There are many applications for pulsed plasma processing. These include destruction of volatile organic hydrocarbons, elimination of hydrogen sulfide from fuel gases, and others where plasmas can induce or accelerate a chemical reaction.

1. Roger Atkinson, Chem. Ro'? 85,69(1985).

2. K. Fujii, 19th Int. Conf. Phenomena in lonized Gases (Il Ciocco, Italy), 1991. 


\section{Ground Penetrating Imaging Radar for Bridge Inspection}

\author{
John P. Warhus, Scott D. Nelson, \\ and Jose M. Hernandez \\ Defense Sciences Engineering Division \\ Electronics Engineering
}

\author{
Hua Lee and Brett Douglass \\ Electronic and Computer \\ Engineering Department \\ Unizersity of Californin Santa Barburn
}

\section{Erik M. Johansson \\ Laser Engineering Division \\ Electronics Engineering}

We have developed conceptual designs, completed requirements analyses, and performed experiments, modeling, and image reconstructions to study the feasibility of improving groundpenetrating imaging radar technology for efficient and reliable nondestructive evaluation of bridges and other high-value concrete structures. In our feasibility study, we made experimental measurements of frequency-dependent electrical properties of cement, from which we derived an electromagnetic (EM) model for concrete, to use in system-level simulations. We performed parameter studies to evaluate key system design issues, using two- and threedimensional, finite-difference, time-domain EM analysis codes to simulate an ultra-wideband synthetic aperture radar and produce simulated radar data for a variety of concrete structures. Images produced from simulated radar data were analyzed to evaluate important radar system performance parameters and characterize imaging algorithms we are developing.

\section{Introduction}

Ground-penetrating imaging radar (GPIR) radiates very-short-baseband (i.e., without a high frequency carrier) electromagnetic (EM) pulse's into ground media such as soil and concrete to probe for features of interest, without disturbing the media. This technology is attractive for use as a bridge inspection $t(x)$ because it is non-contacting and can produce high-resolution reconstructed images of imbedded structural features using a vehicle moving at highway speeds. However, the full capability of the technology has not been exploited at a commercial level. Limitations preventing current ground-penetrating radar (GPR) systems from being more widely used for bridge inspection include difficult data interpretation (no image reconstruction); inaccuratedepth and position measurement; relatively poor spatial resolution; and limited area coverage, which limits operating efficiency.
In an improved bridge inspection CPR system, a mobile ultra-wideband (UWB) radar gathers data for high-resolution image reconstruction of features and defects embedded within the structure. Performance enhancements are achieved by increasing transmitted pulse band width and power, using receiving antenna arrays and synthetic aperture radar processing techniques, and adding highresolution imagring.

An advanced GPIR and imaging system has the near-term (2-to 4-year) potential of addressing critical national and international needs for reliable, cost-effective nondestructive evaluation of bridges and other reinforced concrete structures. There are more than $578,(0)(0)$ highway bridges in the U.S., and more than $40 \%$ of them are either structurally deficient or functionally obsolete. These conditions limit usefulness and can pose a safety threat to the bridge users if the bridges are not properly monitored and maintained. 
Figure 1. GPIR bridge inspection concept.

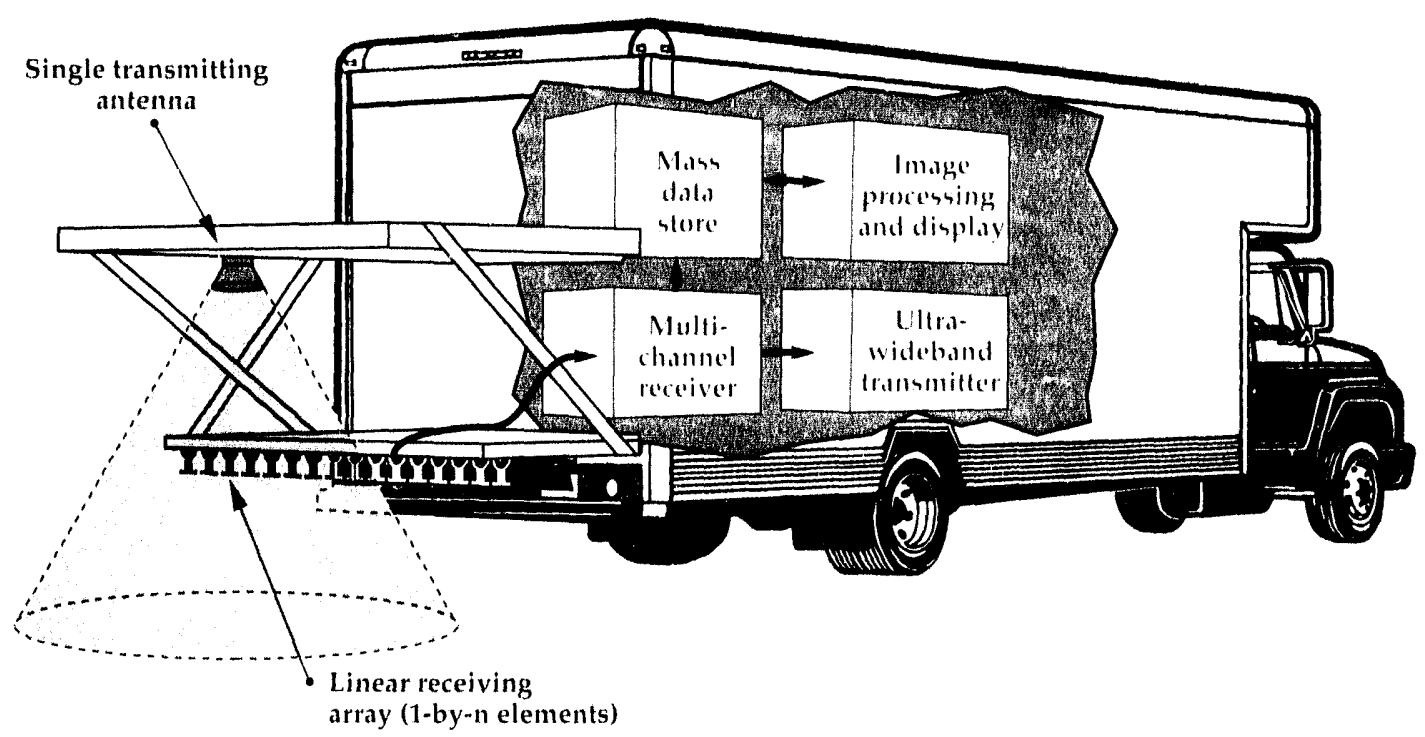

The bridge deck and its wearing surface are the most vulnemble parts of an bridge, andergoing damage from routine service. There are particularly well suited for inspection using a dehickemountad inspection system. The deck has a shorter

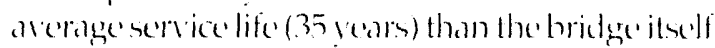
(bs vears). The wering surface, which provides the driving surface and protects the dect benesth it, is ustally designed lo be replaced mans times were the life of the brictge. Concrete shabe with

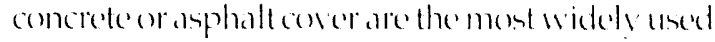

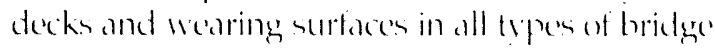
construction.:-

()ur approach in this studs han beren to use system-level deagign, supported by experiments and andetical modeling, to walleste hey ststem performance parameders and reguirements and to determine kersibilits:

\section{Progress}

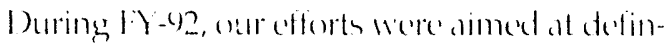
ing reguiroments for imporesing (il'IR performanos

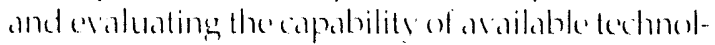

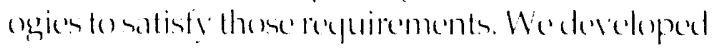
an orerall sistem denigh andept for an improved

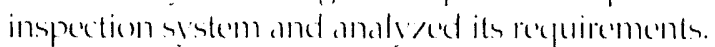
Weinsentigated the electrical properticenterement

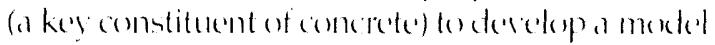
for concerete and to gan insight inte imaging (n)hancement and compection issters. We mexteled redar sisteme and ancrete targed structures to simulate and evaluate interations of LWB Pulaces with clutter soures loggeregate in the comerele,

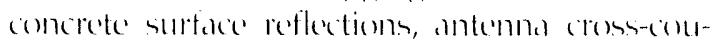

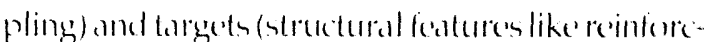
ing bars, or flawe like voide or delaminations). Using analstical capabilities that were improsed during ly y2, wealsoconducted parametric stud-

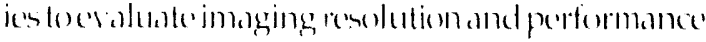

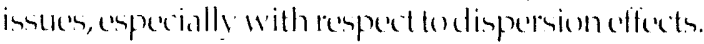

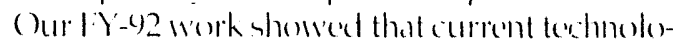

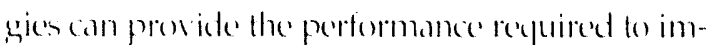
plement an improwed (illk with some limited

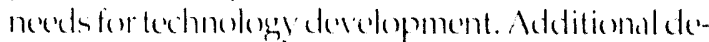
relopment work is reyuired in image reconstrus-

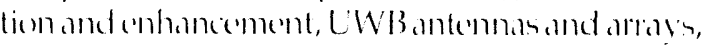
and low-powere, high-repetition-late UWB transmitters. () orr assessment of these develepmental necels inclicatens a high probability of serecess in achiering project gorols.

\section{System-Level Requirements Analysis}

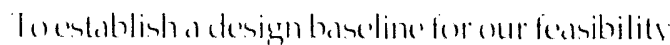

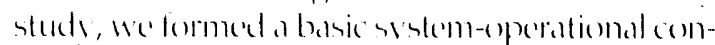

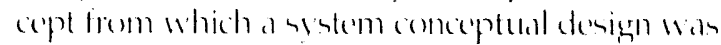
develeped and performance repuiremente rewe defined. Basio operational concept guidedines in-

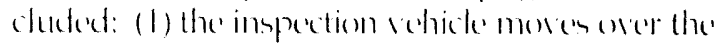

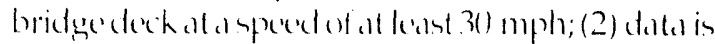
acyuired for one thatfic lane-width of bridge deck

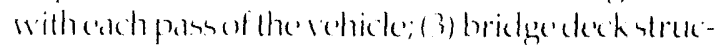
tares aro imspeded to a depthot $0.5 \mathrm{~mm}(4)$ imosges

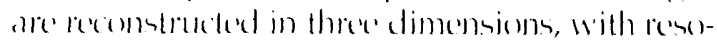

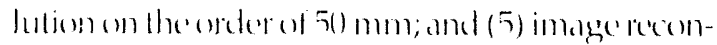
struction is clene off-line, at rates permitting 1010

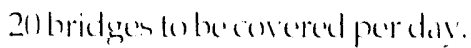

Anshown in Fig. 1, a transmitting antenna and

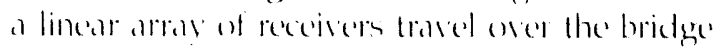




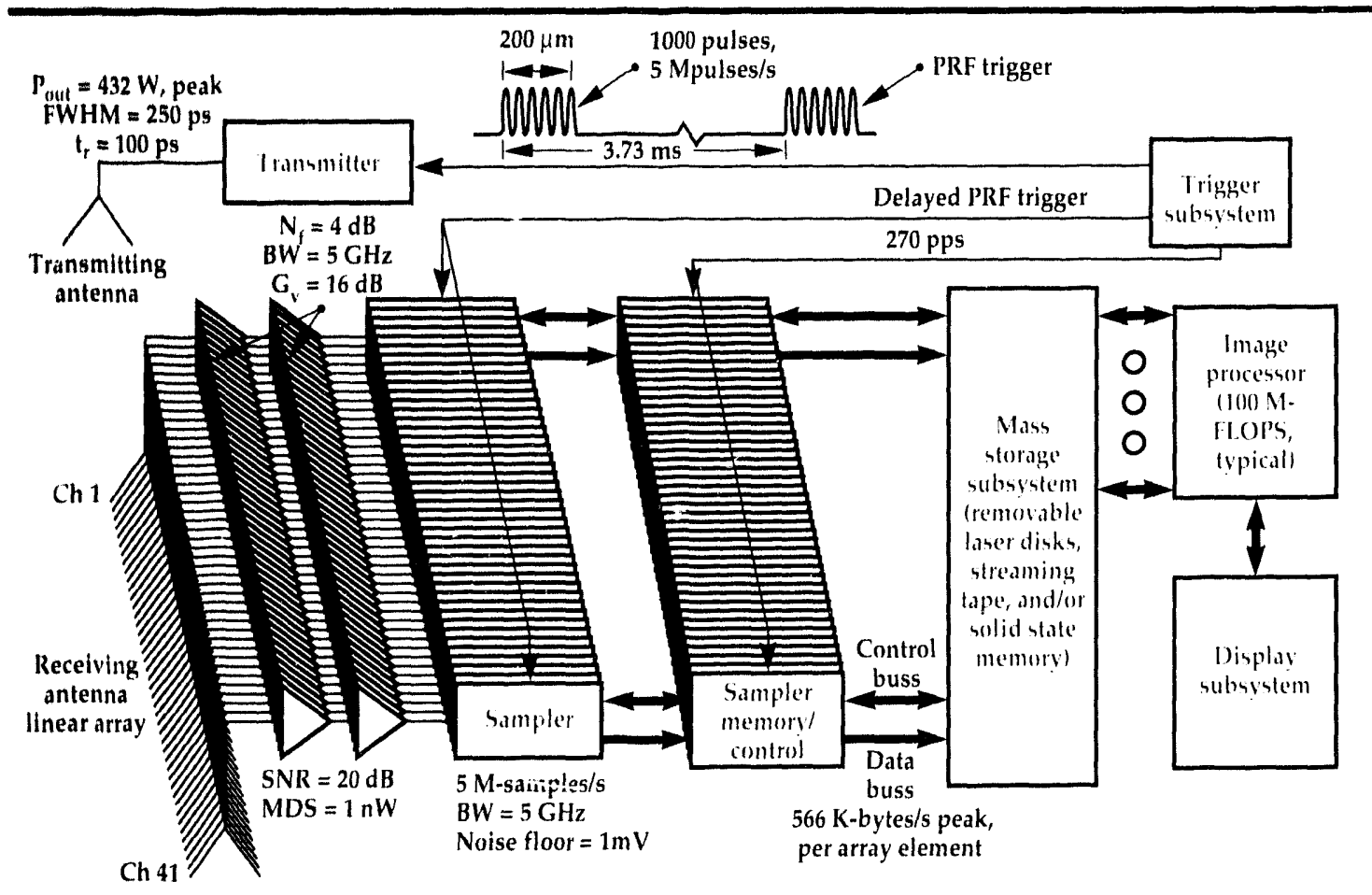

Figure 2. Improved GPIR block diagram.

deck surface, sweepings out a traltic lane-widesinthetre aperture. Data recorded fom the recoivers is transtered via multiple data streame to a mase data storige substestem, from which it cam be as-

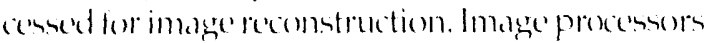
in the renicke of alt centrally located procesings

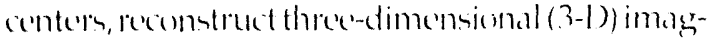
en of the bridge deck structure for evaluation by a brictge inspecter. Image for a bridge 10) 10 m long and four lanes wide are recomstructed in less than an hour:

Vobile data acyuisition, at speeds approxching highwals spered limits, will permit efficient and cost-effectione evaluation of harge areas of bridger dechs in rens short times. Fialuation af reconstructed imagespreduced from the raderedata will allow bridge inspedors to determine bridge comditions, and prieritise maintenance and repara a

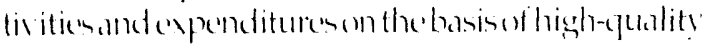
insperctionstatas.

Amore detailed sistem-level concept is illustrated in blextediagram form in Fig. 2. Keys stestem reyurements that we identified and detined for this dengen include: receilere dymamic range and minimum discernible signal; the number of at aiving channels (and arras elements) repuired lo where the desired thaffic hane-width correrage and image renclution; peath and arerige transmitter powar; tramsmitted was transmitting anterum characteristicand pulserep-

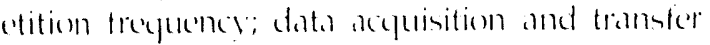

raten; and computatiomal porser reyuired to prosvidedefficient image recomstruction turn-around.

\section{Material Characterization}

Tobetter understand the problem of collecting rachar data and producing images of features (mombededed in a kosst heterogenerous material likecomcrete, we performed broatband (0). to + (ille) s.parameter measurements of transmission (attenuation) and reflectivity of coment somples. These measurements meremadewith a network analyerand a comalal line in which the dielectric material surrounding the conter conductor was formed from cement. Fom the S-parameter data, we calculated the complesdieketric comstant. Mans measurements weremade oner a period of about nine

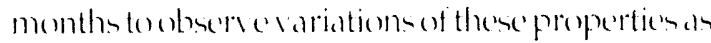
the cement curced.

Figure 3 shomstypical renultont medsurements and calculations for a coment ample at coisht and 204 dass after it was poured. The decreasen in

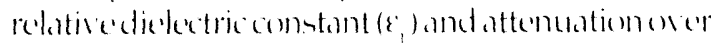
time reflect the reduction of the amount of tree Water within the curing coment. Important comse-

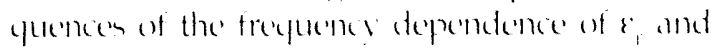

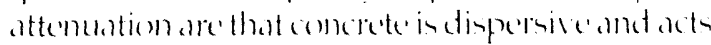

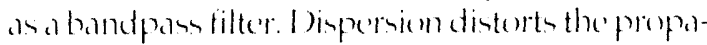

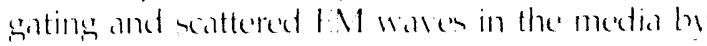
reducing risctime and increaning pulse width, and

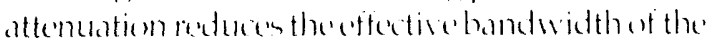




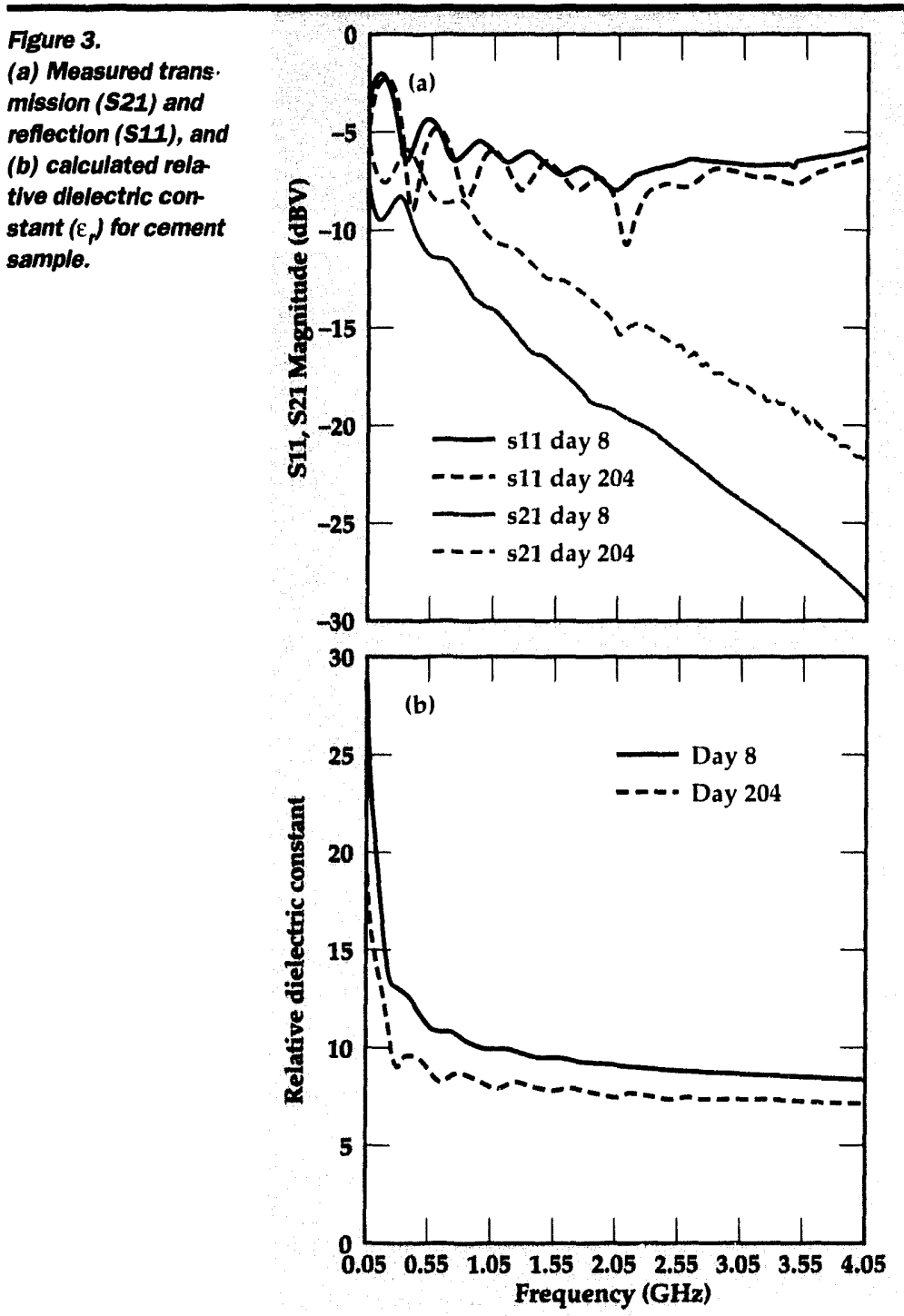

Figure 4. Results from (a) 1-D experit mental data and (b) 1-D cement modt el.

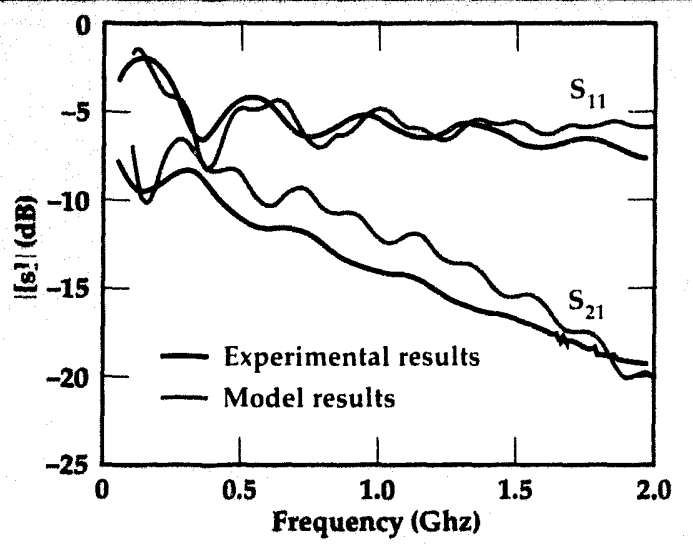

EM energy. These effects degrade the resolution of images reconstructed from the UWB radar data and cause errors in depth measurement.

Data obtained from these measurements were useful in defining the dominant electrical parame- ters of concrete required for accurate modeling using analytical codes like AMOS or TSAR. In addition, knowledge gained from these measurements provided insights into ways in which correction and enhancement of radar data can be achieved.

\section{Modeling and Image Reconstruction}

A key element in our studies of system performance requirements was EM modeling of radar system components and targets. Our modeling requirements included needs for one- , two- , and three-dimensional simulations. Those requirements covered a variety of issues important to our feasibility study, including: developing and validating an EM model for concrete; modeling complex bridge-like structures to support our image reconstruction algorithm development effort by providing a means to evaluate algorithm performance; and performing trade studies that examined radar system configuration options and performance parameters.

To satisfy our requirements, we used two finite-difference time-domain EM analysis codes, which were developed and are maintained by Lawrence Livermore National Laboratory. Those codes, AMOS and TSAR, permitted us to evaluate a wide range of technical issues, without requiring the investment of limited project resources to produce physical hardware or execute numerous experiments. In support of our need to model a dispersive material, both codes were upgraded to permit modeling EM wave propagation and scattering in a medium whose dielectric properties are frequency dependent.

By combining results from early material characterization experiments with analytical modeling tools, we developed an EM model for concrete. Permittivity data derived from material characterization measurements were used in a onedimensional (1-D) model to simulate those measurements. Figure 4 is a plot of measured data overlaid with results from the 1-D model, showing good agreement between measurements and the model.

To extend these results to two dimensions, an additional experiment was performed. UWB pulses were launched through a concrete block, using a broadband antenna, and detected and recorded on the other side of the block with a UWB sensor and recording system. A two-dimensional (2-D) model of the experiment was constructed and run using AMOS. The model used the complex permittivity data from the 1-D case, and included 
such details as the antenna beamwidth, radiated electric field waveform, dimensions of the block, dispersive effects of the cement, and clutter effects produced by the aggregate within it. Figure 5 shows plots of both the experimental measurements and simulated results. Again, fairly good agreement between experiment and simulation provided validation of the concrete EM model.

After confirming the validity of our 2-D EM model for concrete, this analytical tool was used extensively to evaluate radar system design parameters and image reconstruction algorithm performance. Parametric studies we conducted using this model are summarized in Table 1. Image reconstructions were made from the simulated radar data for most of the cases listed in the table. The images aided assessments of the impacts of design parameter changes on overall system performance and complexity, and in evaluating image quality for specific imaging techniques. In addition to the studies listed in the table, 2-D simulations permitting evaluation of air/concrete boundary and antenna cross-coupling effects, and of the impact of using multiple transmitters as well as multiple receivers were also run. These studies helped to confirm conceptual design conclusions and permitted us to consider other more complex system configurations.

An example of results from one important study is shown in Fig. 6. A series of simulations was run in which a single target of fixed size was embedded at increasing depths within the concrete. The purpose of this series was to evaluate imaged range and cross-range resolution of the reconstructed target and to assess the accuracy of the position location of the target after corrections for dispersion effects had been made. The image sequence was reconstructed using a multi-frequency holographic method, which includes a correction for the effects of dispersion.
Table 1. Model-based parametric studies.

\begin{tabular}{ll}
\hline Parameter & Variations \\
\hline Radiated pulsewidth & 100 to $1000 \mathrm{ps}$ \\
$\begin{array}{l}\text { Array clement spacing, } \\
\text { spatial sample rate }\end{array}$ & 5 to $45 \mathrm{~mm}$ \\
Target cross-section size & 5 to $75 \mathrm{~mm}$ \\
Target depth & 10 to $150 \mathrm{~mm}$ \\
Clutter source (aggregate) density & 10 to $50 \% \%$ \\
Target density/type & $\begin{array}{l}\text { No targets, } 1 \text { void, } 2 \text { reinforcing } \\
\text { bars (rebars), } 2 \text { rebars plus } 1 \text { void, a } \\
\text { rebar grate, and rebar shaded from } \\
\text { EM radiation by other rebars }\end{array}$ \\
\hline
\end{tabular}

The degrading effects of dispersion and frequency-selective filtering on resolution are clearly shown in these images. As predicted from material characterization measurements and analysis, while the target's dimensions remain fixed, its image increases in size in both down-range and cross-range directions as its depth increases. However, careful analysis of the images shows that the target depth, as indicated by the peak of the image intensity, is located quite accurately when dispersion corrections are applied. The only esception is the case very close $(10 \mathrm{~mm})$ to the transmitter and receiving array. The most likely cause for the error, in that case, was EM wave interference that occurred because the reflected pulse from the target was incident on the receiving antennas, while the tail of the transmitted pulse was still propagating past the receivers.

The three-dimensional (3-D) EM modeling effort was started late in the year, to support testing
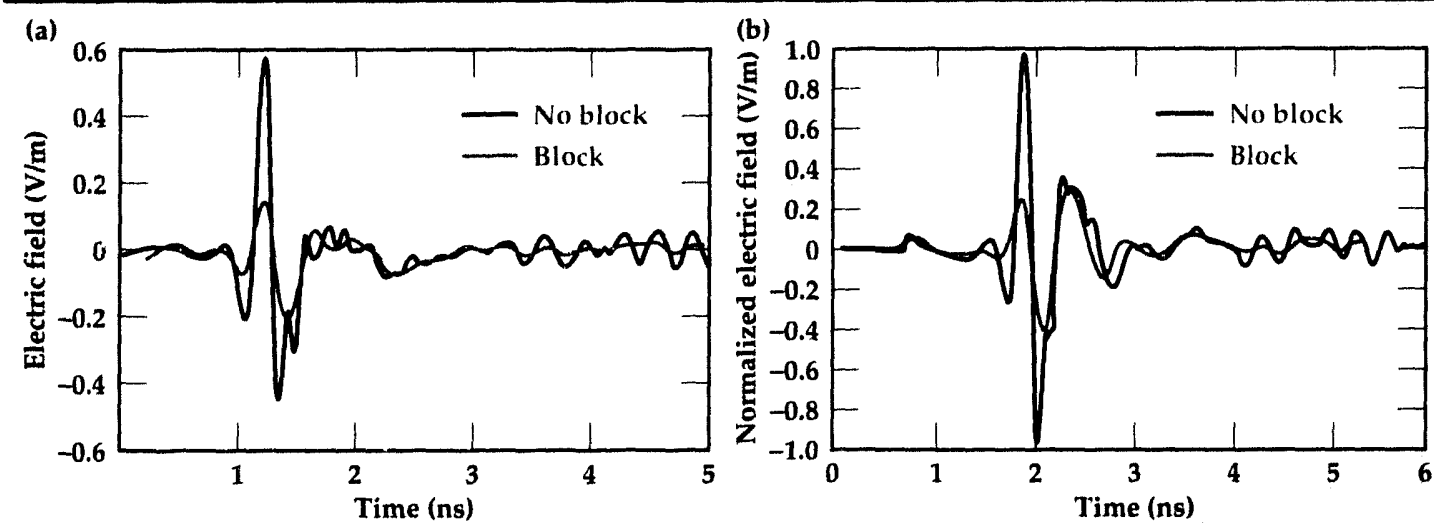

Figure 5. Results from (a) 2-D experimental data and (b) 2-D concrete model. 


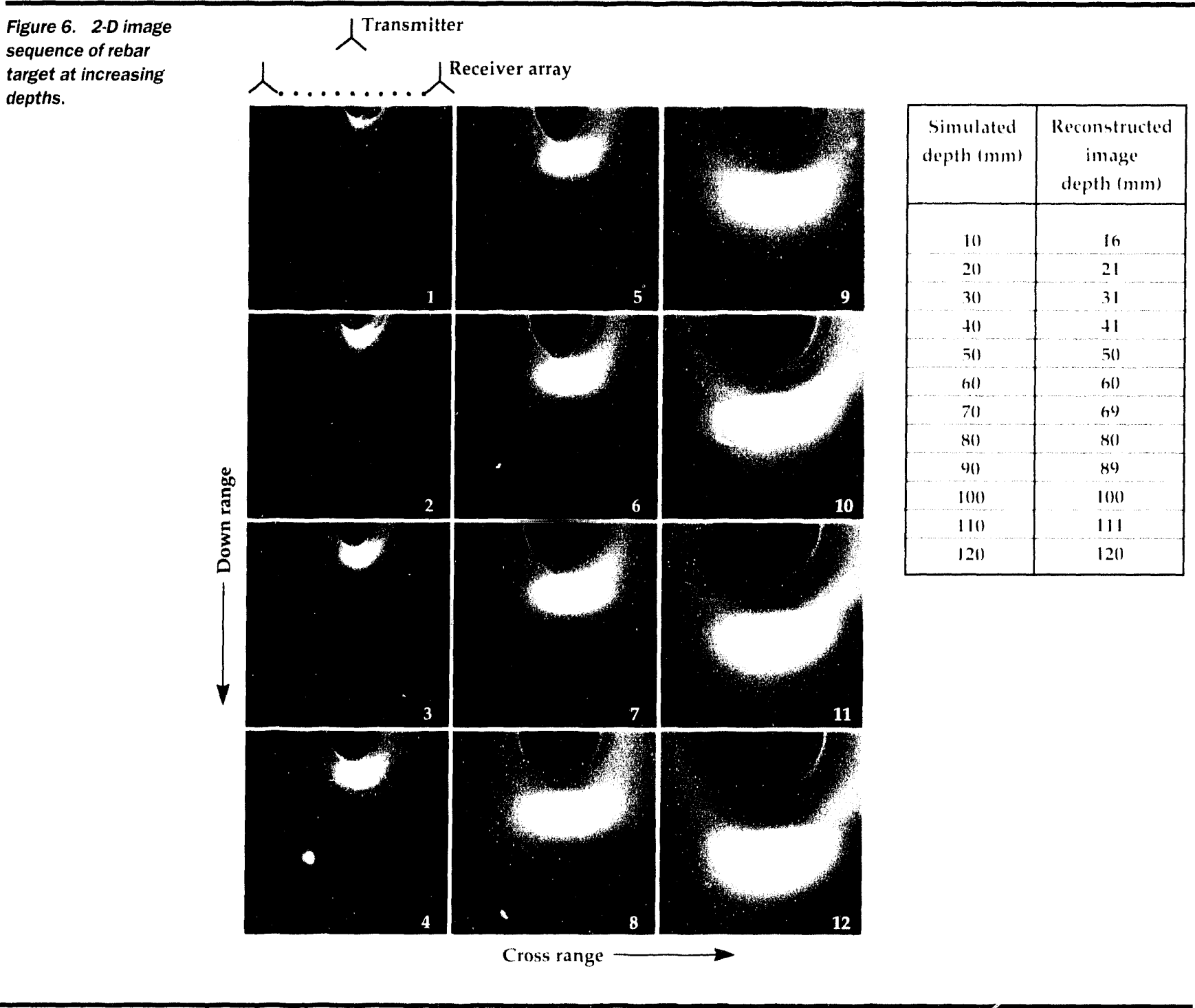

Figure 7.

(a) Physical model of four rebars in free space and

(b) volumetric rendering of 3-D image reconstruction. (a)

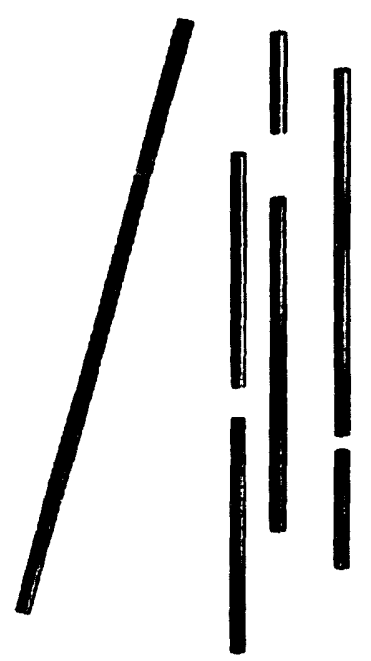

(b)

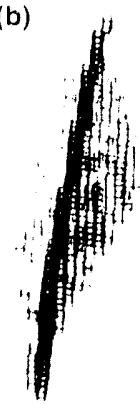

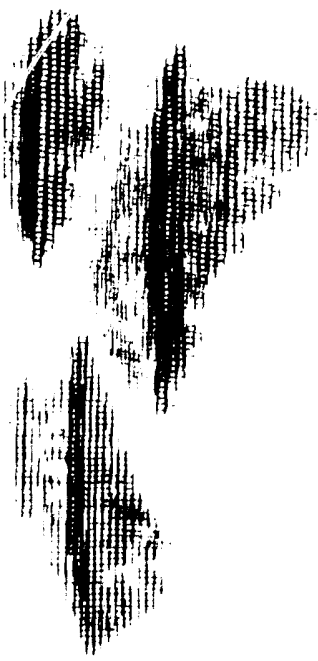


of 3-D image reconstruction software. Very simple physical models were used in the early tests. An example of a test case is shown in Fig. 7. in which four rebars, three of which have gaps, are assembled in free space. This simple model permitted evaluation of the imaging software without including the complicating effects of clutter, dispersion, and filtering. After the image was reconstructed, it was processed and enhanced with some rudimentary techniques to provide a means for viewing the 3-D rendering as shown in the figure.

Images of the rebars are clearly visible in the rendering; however, the gaps in the bars are not. The gaps are not seen in the rendering because they did not produce any reflection of the EM energy launched in the simulation, and the energy scattered from the rebars tends to fill in the voids. In the case where air-filled gaps in rebars are embedded in concrete, we do expect to detect and image the gaps because the air/concrete interface at the gap will produce a significant phase reversed reflection.

\section{Future Work}

Our continuing efforts are aimed toward a field demonstration of a limited-capability prototype system late in the next fiscal year. To support that effort, we will complete a series of experiments to confirm key modeling results and verify system design parameters. Those experiments will be conducted using a concrete test slab that was designed to simulate bridge construction features, and in which we embedded several flaw simulants. UWB antemna and transmitter development will be pursued, and image reconstruction algorithm development, testing, and refinement will continue with the goal of having optimized radar hardware and imaging code available late in the year to support the demonstration. A low-cost prototype system will be designed to permit demonstration of base data acquisition and image reconstruction performance. The objective of the demonstration will be to show improved performance in resolution, and accurate reconstruction of embedded structure.

\section{Acknowledgements}

We wish to thank Jim Brase, Remote Sensing, Imaging, and Signal Engineering Thrust Area Leader, and John DeFord, Computational Electronics and Electromagnetics Thrust Area Leader, for their support in supplying the resources needed to develop and evaluate imaging techniques, to perform EM modeling, and to enhance the capabilities of EM modeling codes for this project.

1. Our Nation's Highanlys: Selected Facts and Figure's, U.S. Department of Transportation, Federal Highway Administration, Publ. No. FHWA-PL-90-024.

2. N.P. Jones and B.R. Ellingwoxd, "NDE of Concrete Bridges: Opportunities and Research Needs," Federal Highway Administration Conf. on NDE for Bridges (Arlington, Virginia), (August 25-27, 1992). 


\section{High-AveragePower, Electron Beam-Controlled Switching in Diamond}

\author{
W. Wayne Hofer \\ Defense Sciences Engineering Division \\ Electronics Engineering
}

\section{Don R. Kania}

Inertial Confinement Fusion Program

Laser Programs

\author{
Kart H. Schoenbach, \\ Ravindra Joshi, and \\ Ralf P. Brinkmann \\ Old Dominion University \\ Norfolk, Virginia
}


Table 1 Electronic properties of dlamonds.

\begin{tabular}{lccc}
\hline & Microwave films & $\begin{array}{c}\text { Single-crystal } \\
\text { natural Il-A }\end{array}$ & Homoepitaxial film \\
\hline Thickness & $25-500 \mu \mathrm{m}$ & $1 \times 1 \times 3 \mathrm{~mm}^{3}$ & $120 \mu \mathrm{m}$ \\
Grain size & $10-100^{\prime} \mathrm{s} \mu \mathrm{m}$ & single-crystal & single-crystal \\
$\begin{array}{l}\text { Electrical } \\
\text { resistivity }(\Omega-\mathrm{cm})\end{array}$ & $10^{5}-10^{11}$ & $>10^{11}$ & $>10^{11}$ \\
Lifetime (ps) & $100-800$ & & $100-1000$ \\
Mobility (cm $\left.{ }^{2} / \mathrm{Vs}\right)$ & $500-4000$ & 2800 & 150 \\
Raman & $1330-1334$ & 1332.4 peak & 3000 \\
& FWHM 4-9/cm & (FWHM 2.4/cm) & $\begin{array}{r}1332 / \mathrm{cm} \text { peak } \\
(\text { FWHM } 2.9 / \mathrm{cm})\end{array}$ \\
\hline
\end{tabular}

ties of diamond and its superior thermal properties are combined with microchannel cooling and the rapid advance in CVD technology, diamond becomes an excellent solid-state material for advanced, high performance power electronics.

\section{Progress}

In our switch (Fig. 1), a high concentration of carriers (corresponding to $\mathrm{kA}$ 's $/ \mathrm{cm}^{2}$ ) are created by ionization when a high voltage, low current

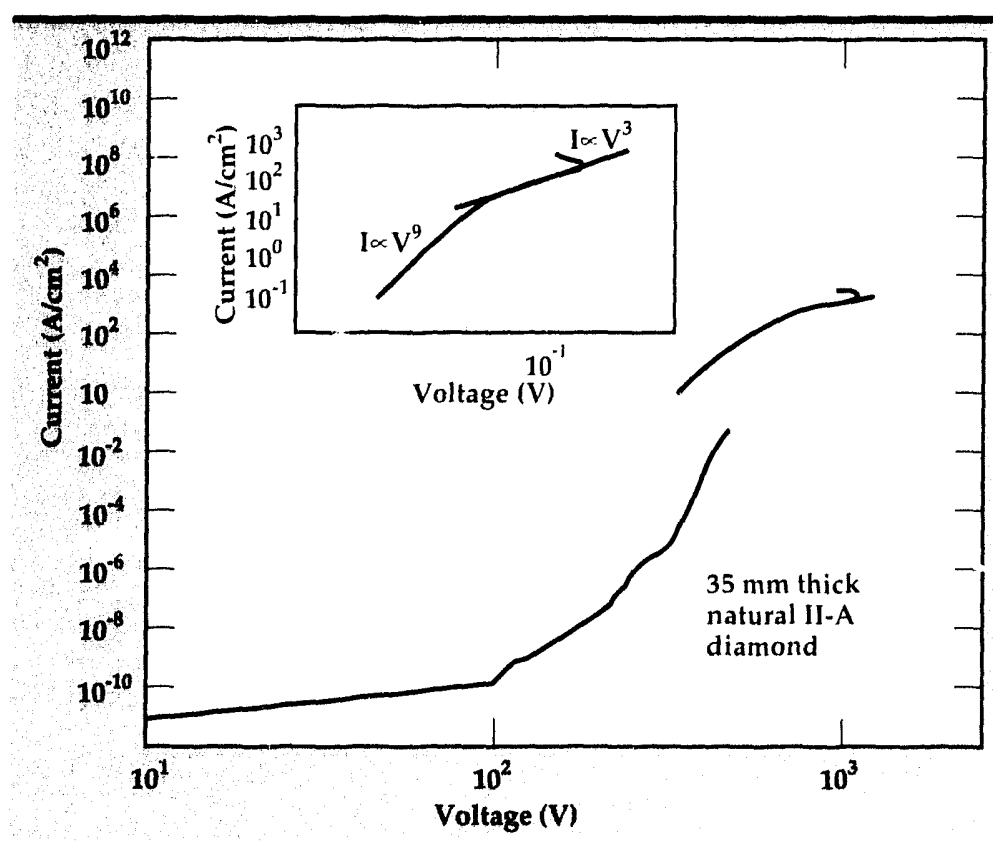

Figure 2. Dark current vs applied voltage for 35- $\mu \mathrm{m}$ natural II-A dlamond film. The current increases rapidly once the trap-filled limit is reached $(\sim 200 \mathrm{kV} / \mathrm{cm})$. Similar results were obtained for 50 um-thick diamond, but the dark current increased rapidly at about $400 \mathrm{kV} / \mathrm{cm}$. electron beam is absorbed in the diamond film. The controlling electron beam can be generated and modulated at megahertz frequencies by compact, long-life, commercially available grid-controlled thermionic cathodes. As an alternate to thermionic cathodes, recent research and development of new high-current-density electron sources, such as ferroelectric cathodes, micro-field emission cathodes, and even diamond field emission cathodes, could potentially be combined with a thin film diamond to create a very compact, robust, high power solid-state diamond switch.

Our FY-92 goals were to identify and address technical issues that could potentially limit the anticipated performance of electron beam-triggered, high power switching in diamond. In particular, we concentrated on the role of contacts and nonlinear effects at high electric fields, electron beam range in diamond, and carrier transport modeling. Our work is a combined effort with researchers at Old Dominion University at Norfolk, Virginia, and at LLNL.

\section{Contacts and Nonlinear Effects}

Diamond is normally thought to be an excellent high voltage insulator. However, we have shown that for both natural and CVD diamond on silicon, the dark current (no electron beam-generated carriers) increases by $10-11$ orders of magnitude at high electric fields.

For natural II-A diamond, the strong nonlinear increase starts at $200-\mathrm{kV} / \mathrm{cm}$ for $35 \mu \mathrm{m}$-thick diamond (Fig. 2) and at $400-\mathrm{kV} / \mathrm{cm}$ for $50 \mu \mathrm{m}$-thick diamond. We believe that this threshold corre- 


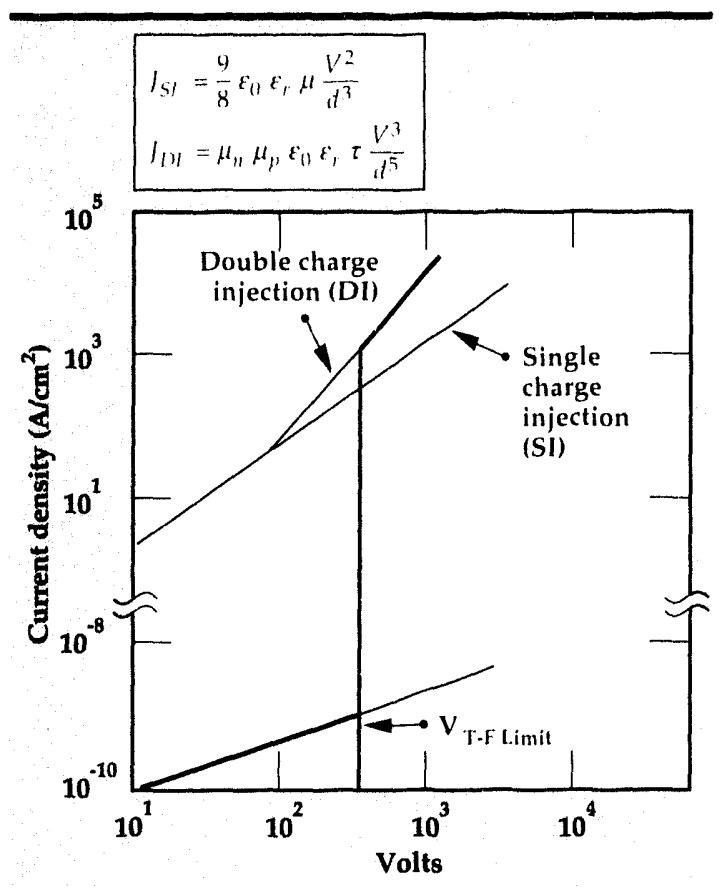

Figure 3. Drift-diffusion modeling results. A model based on charge injection qualitatively predicts the rapid increase in current at high electric fields.

sponds to the trap-filled limit. The thickness dependence correlates well with photoelectronic theory where the trap-filled-limit electric field is proportional to the square of the material thickness. As the field is further increased, dark current is dominated by charge injection at the contacts. Both our qualitative and more comprehensive driftdiffusion modeling results (Figs. 3 and 4) predict these results. At even higher fields, a negative differential resistivity phase quickly leads to de-

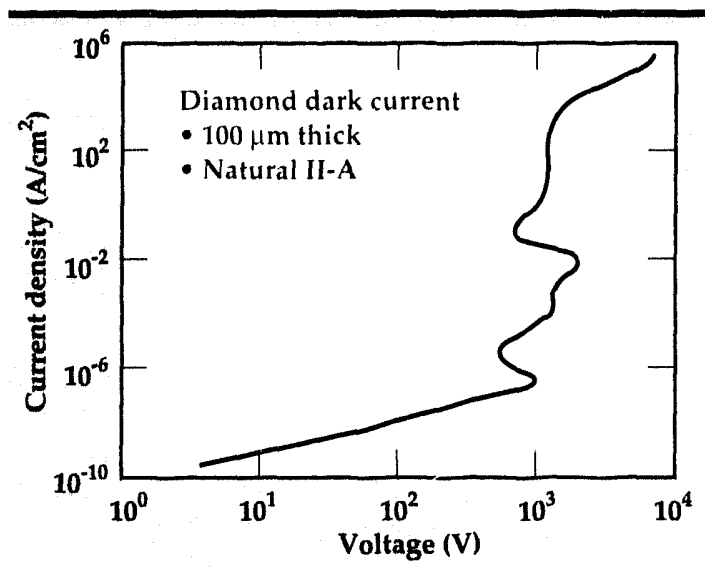

Figure 4. Drift-diffusion modeling results. Data from our drift-dlffusion model with injecting contact and deep trap centers agree with the behavior observed qualitatively and experimentally.

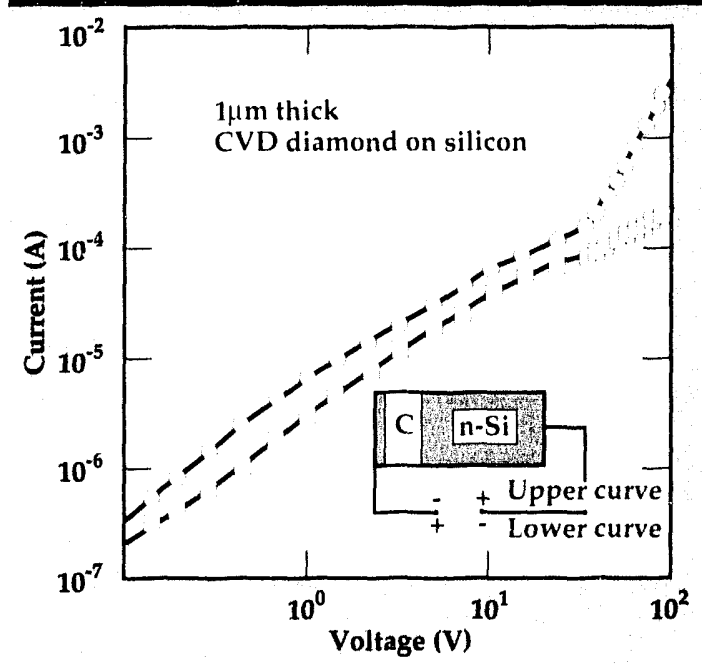

Figure 5. Dark current vs voltage for $1-\mu m$-thick $C V D$ diamond on n-silicon. The onset of rapidly increasing dark curr.nt depends on the polarity of the bias. When the silicon is biased negative, the hold-off voltage is highest.

struction of the switch, most likely due to current filaments.

Similar to natural diamond, the dark current in CVD diamond on a heavily doped $\left(\sim 10^{18}\right.$ $\mathrm{cm}^{-3}$ ) n-silicon increases rapidly at high fields (Fig. 5). However, the electric field threshold was in excess of $0.9 \mathrm{MV} / \mathrm{cm}$, much higher than that for natural diamond, and it depends strongly on the bias polarity. Apparently silicon is a very

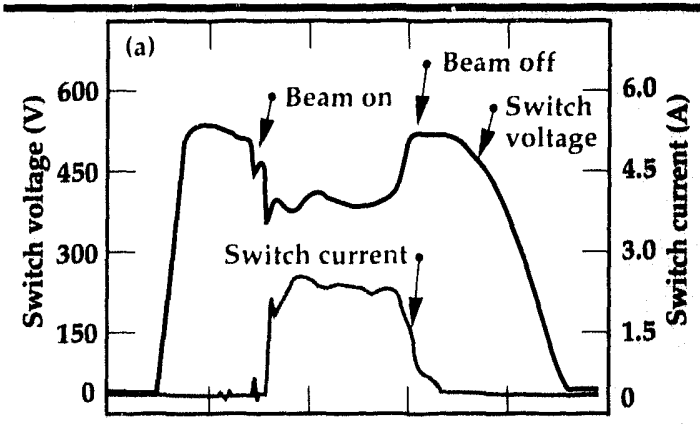

Figure 6. Voltage vs time for electron beam-switched, 35- $\mu$ m-thick, natural II-A diamond at two different bias levels. At the lower field (a), the conductivity forlows the electron beam, but at the higher field (b), the current continues after the beam is turned off, due to

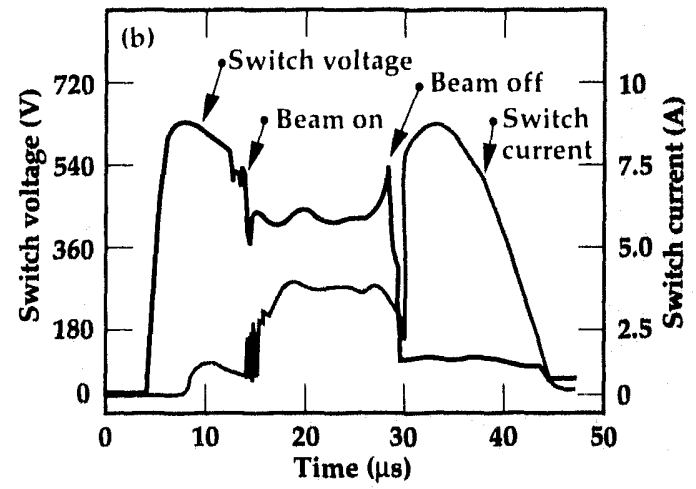



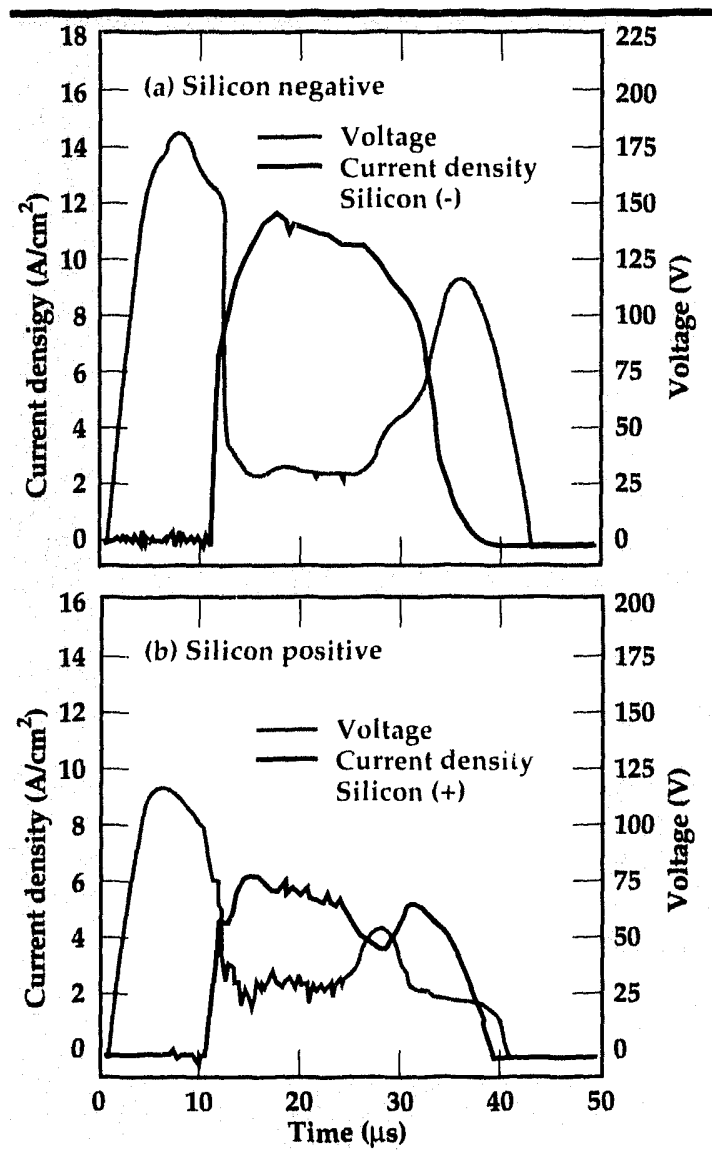

Figure 7. Electron beam-induced conductivity in 1-1m-thick CVD diamond on n-silicon for opposite polarities. When the n-silicon is negative (a), the switch conductivity follows the beam current. However, when the n-silicon is positive (b), the switch conductivity persists after the beam is turned off.

good blocking contact.

Dark current in diamond is highly dependent on carrier recombination and trapping at deep energy levels in the diamond and whether contacts are blocking or injecting.

\section{Electron Beam-Induced Conductivity}

When the natural diamond switch is irradiated with an electron beam, the switch conductivity follows the beam profile at lower electric fields; but at higher fields, the switch remains conducting when the beam is turned off (Fig. 6). At even higher fields, the switch failure is likely due to filamentary current. We believe this corresponds to operation in the negative differential resistivity mode.

When irradiated with an electron beam, the conductivity of the CVD diamond follows the beam profile (Fig. 7) up to $1.8 \mathrm{MV} / \mathrm{cm}$ when the silicon is biased negative. However, when the silicon is biased positive, the CVD diamond remains
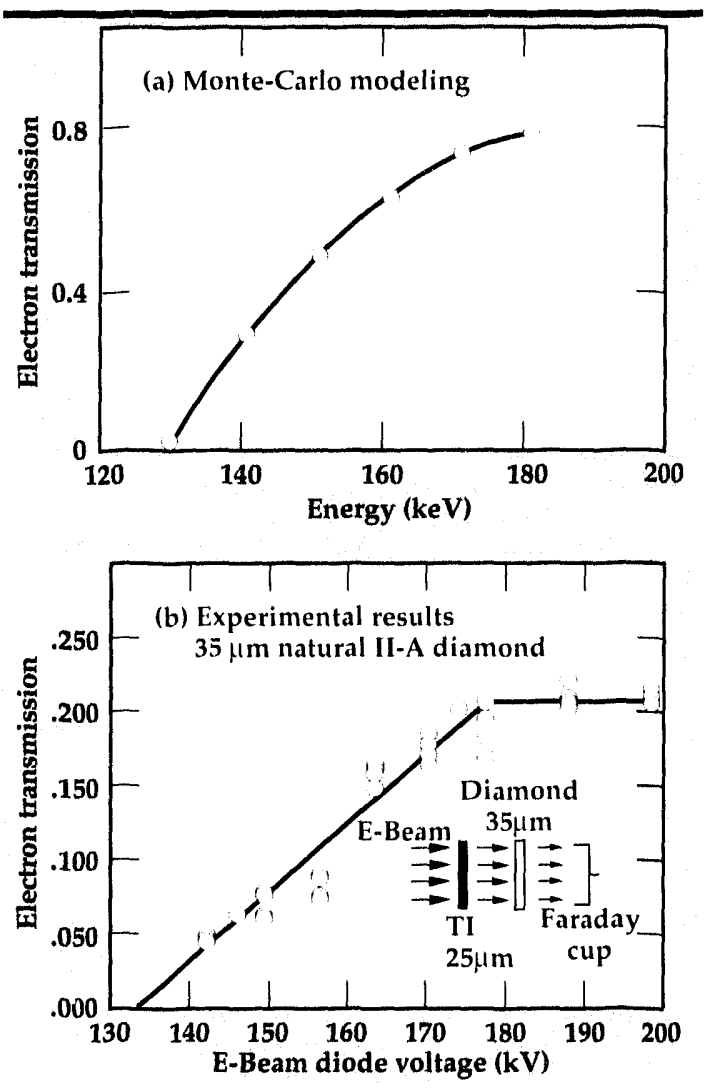

Figure 8. (a) Monte-Carlo calculations of 150-keV electron beam penetration in 35 $1 \mathrm{~m}$ diamond. Scattering effects in a 25 1. $\mathrm{m}$ Ti anode foil are included. (b) Transmission of the electron beam in a 35- $1 \mathrm{~m}$.thick natural diamond film. The electrons are completely absorbed at about $130 \mathrm{keV}$.

conducting even when the beam is turned off.

Based on these data, it appears that CVD diamond on silicon may limit carrier injection, thus enabling us to switch higher voltages.

Based on our current data, we should be able to switch voltages ranging from 400 to $4000 \mathrm{~V}$. If the lock-on field can be extended 5-10 times by tailoring the diamond grow th and contacts, we may be able to produce an on-off switch operating at 20 to $40 \mathrm{kV}$.

To hold-off and switch higher voltages, we must extend the onset voltage threshold of the rapidly increasing dark current by using better blocking contacts.

\section{Electron Penetration Depth}

Electron penetration depth deternines the maximum diamond thickness for a given electron beam energy. The diamond thickness in turn determines the maximum hold-off voltage.

Modeling results show that the penetration depth for $150 \mathrm{kV}$ electrons in diamond is about 
$35 \mu \mathrm{m}$ (Fig. 8a). These results are confirmed by our experimental data (Fig. 8b).

\section{Future Work}

To switch the highest possible voltage and power, we must extend the electric field threshold of the nonlinear increase in dark current. This will be accomplished with non-injecting contacts (block. ing contacts) and by understanding and controlling deep-trap center impurities in the diamond switch. We will concentrate our efforts on CVD diamond grown on highly doped silicon and determine how voltage hold-off scales with diamond thickness.
We will obtain data on deep-center impurities and defects in diamond by using Electron BeamInduced Current Transient Spectroscopy'(EBICTS). EBICTS spatially resolves the activation energy and density of deep-level traps. These data will be used in our drift-diffusion models that calculate carrier transport in diamond at high electric fields.

Finally, we will construct a prototype switch to demonstrate kilovolts switching in diamond and a range of hundreds of amperes.

1. R.H. Bube, Plotoclectric Properties of Simicondertors, Cambridge University Iress (Cambridge, England), 1992 . 


\section{Testing of CFC Replacement Fluids for Arc-Induced Toxic By-Products}

\author{
W. Ray Cravey \\ Defense Sciences Engineering Division \\ Electronics Engineering
}

\author{
Ruth A. Hawley-Fedder and \\ Linda Foiles \\ Condensed Matter and Analytical \\ Sciences Division \\ Chemistry and Materials Science Department
}

\author{
Wayne R. Luedtka \\ Computer and Communication \\ Engineering Livision \\ Electronics Engineering
}

We have developed a unique test-stand for quantifying the generation of perfluoroisobutylene (PFIB) in chlorofluorocarbon (CFC) replacement fluids when they are subjected to high electrical stress/breakdown environments. PFIB is an extremely toxic gas with a threshold limit value of $10 \mathrm{ppbv}$ as set by the American Conference of Governmental Industrial Hygienists. We have tested several new fluids from various manufacturers for their potential to generate PFIB. Our goal is to determine breakdown characteristics and quantify toxic by-products of these replacement fluids to determine a safe, usable alternative for present CFC's. We are currently working with $3 \mathrm{M}$, DuPont, and Ausimont, key manufacturers of these replacement fluids, to test them for potential PFIB generation.

\section{Introduction}

Restrictions on the use of chlorofluorocarbons (CFC's) worldwide, nationally, and at Lawrence Livermore National Laboratory (LLNL) will have an enormous impact on industry and government laboratories. On September 16, 1987, several CFC-producing nations including the United States signed the Montreal Protocol, which called for the phase-out of production of CFC's no later than the year 1997. President Bush, reacting to scientific data showing the imminent danger of an ozone hole over the Northern Hemisphere, ordered the phase-out of CFC's by the year 1995, two years early than the Montreal protocol. ' Worldwide usage of CFC is estimated at 750,000 metric tons ${ }^{2}$ (see Fig. 1). Almost half of this amount is used either as cleaning agents in electronic PC board manufacturing $(24 \%)$, or in the foam blowing industry (another $24 \%$ ). The majority of the remaining CFC use is in refrigeration and aerosol sprays. CFC's are used extensively in the automobile industry, as well, as a refrigerant for vehicle air conditioners. Although several replacements for existing CFC's do exist, many of these replace-

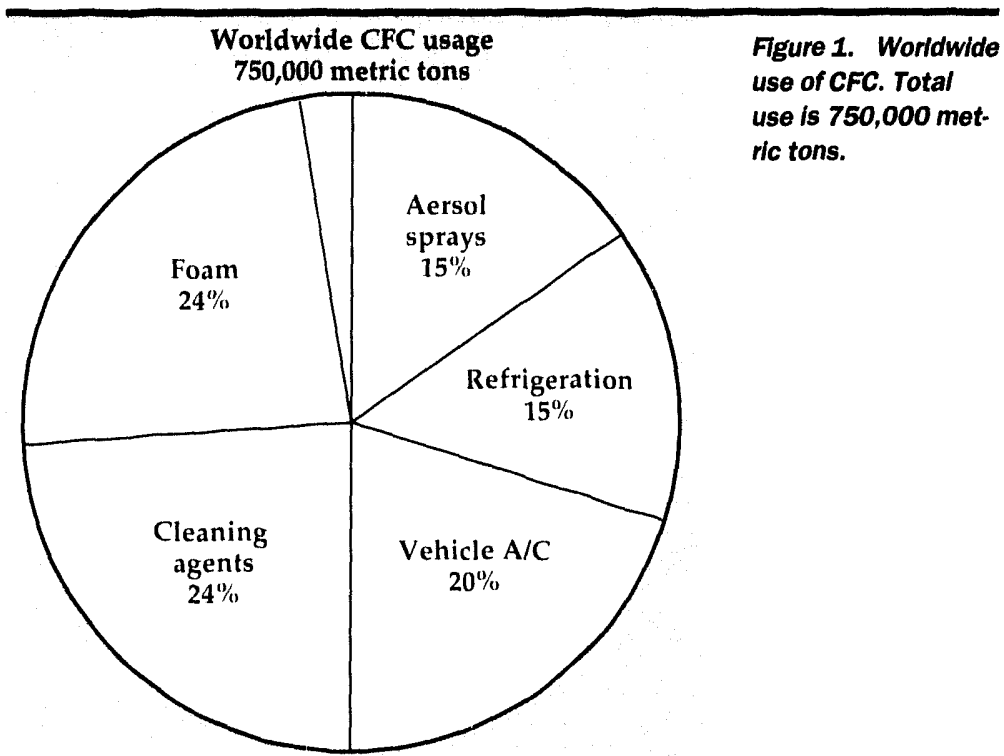




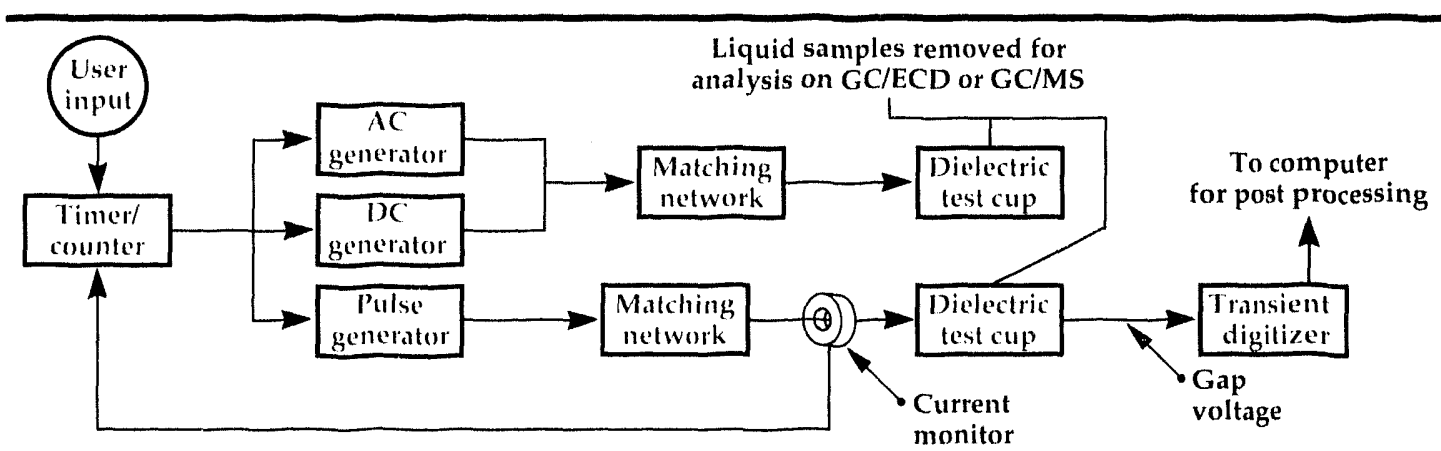

Figure 2. Block diagram of CFC replacement fluid test-stand. The user sets the time or number of pulses for the desired test: $A C, D C$, or pulse. The output of the corresponding generator is fed through a matching network into the dielectric test cup. The test cup houses the gap electrodes and contains the fluid under test. Samples are removed from the test cup and analyzed on a gas chromatograph (GC) or GC mass spectrometer, to quantify the amount of PFIB that was produced, if any. The voltage across the gap and the coinciding current are digitized and recorded on a computer. There they are analyzed, and the power and energy are determined.

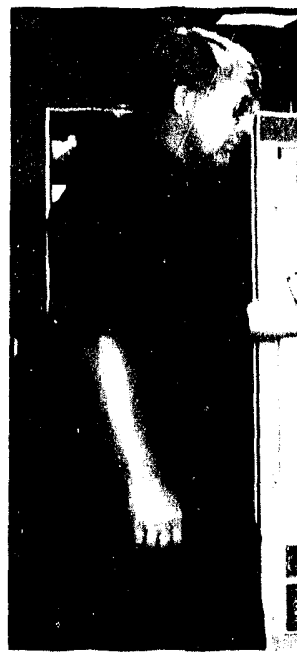

Figure 3. Photo of test-stand. ments are texic, ' hommuble, or highly expensive. In addition, two replacements, although not toxic, have beem identified as (1/a) depletion agents, and their use will be phased out in the near future.

We are studying sereral new" replacement fluids

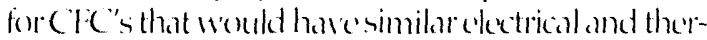

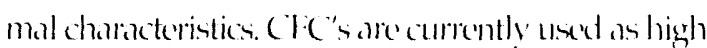
voltage electrical insulatorsand dievertric contants for

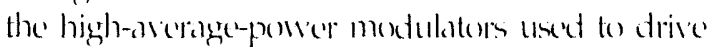
the copper vaper lasers at the $A$ temic Vaper I I seser

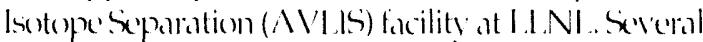
substitutes have been suggested to replace these fluids. But a stumbling blexk assexialed with the'se re

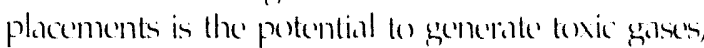
stach as l'llib, when the fluids are subjected to high

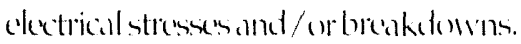

\section{Progress}

Orer the hast vear, we designed, fabricated, and tested the new (1) replacement fluid fest-stand, which wastour foremest goal. Work is prexereding on the compressieve data collection and analysis that is necessary to guantify the toxic by-product production for given breakdow'n conditions. Initial results from texts conducted with the test-stand show a linear trend with respect to are energy. Wo have received funding from the Superconducting Super Collider (SSC) for analysis and testing of the cox)ling fluid used in their low-energy boster (LEB) car ities. Amoredexoriptivesummary of ourprogressis griven in the sulpseyuent sertions.

\section{Replacement Fluid Test-Stand}

Wo hase identified three electrical breakdown/ stressenviromments that may contribute to liflib prerdextion in C FC replacement candidates: $\triangle C$ broakdewn; high I X ficld stress; and pulsed beaketown. ( har test-sitand was designed to simulate all there of these enviromments. A block diagram and description of the operation of the test-stand are given in Fig. 2; Fig. 3 is a photegraphof the test-sitand.

An important test that has sapplication in the refrigs(ration industry is breakedown due to high $A C$ voltages. We hase the capability of preducing (x)-H 1 AC, high voltage breakelown anditions with voltages ranging from (oto +1$) \mathrm{kV}$, and any desired gap spacing acrosis the test coll electrodes. () or capabilities allow uste simulate the inside environment of the erdinary refrigeration compresion/motor asiombly:

l figh I C fickd stress (xecurs in many situations where there are high voltages present. Eilextrical areing is not asseriated with these conditions; howerer, there can be extremely high fields and oroma onselt. With our system, we are able to generate these high pre-breakitown fickds in the fluid-under-test for any presed time limit. After the given time limit, the fluid is ancalyed for Prib formation. 
Pulsed breakdown environments are protuced with many high voltage medulators. Typically, these' modulators are used for driving radars, lasers, and accelerator cells. We have a wide range of pulsed conditions that can be produced with our present test-stand. In addition to being able to produce the pulsed conditions mentioned, we have implemented a complete electrical diagnostic system for measuring the breakdown voltage, discharge current, arc pow(ri, and energy that are associated with each pulse. Through the use of the data that is recorded by the diagnostics, we are able to correlate the quantity of IPFIB protuced with the pertinent control variables, such as voltage, current, pulse-width, pulse repetition frequency (prf), and energy.

\section{Experimental Results}

Measurements have been made on a candidate replacement fluid for the copper vapor laser modulators. The fluid was subjected to a $3(0-k V$ pulse at a pulse repetition rate of $75 \mathrm{~Hz}$, with a full-width halfmaximum of $100 \mu$ s. A 10-mil gap spacing with brass electrodes conforming to ASTM standards ${ }^{5}$ was used for testing. The dielectric test cup was filled with $85 \mathrm{ml}$ of the fluid under test. Samples were taken from the dielectric test cup before exciting the fluid, at $20 \mathrm{kV}, 40 \mathrm{kV}$, and $100 \mathrm{kV}$ pulses. Between each sample interval, the voltage and current waveforms were recorded, and the instantaneous power and energy were calculated for the arc. A typical data set is illustrated in Fig. 4.

There are two loss mechanisms associated with the are discharge: resistive/inductive phasen losses and conduction loss. The resistive/inductive phase losses are produced during the time the voltage collapses across the gap and the current begins to rise. During this phase, there is a power and energy loss associated with the instantaneous current rise and voltage collapse. The faster the voltage collapses, the less appreciable these losses are. The second loss medanism, which appears to be the most dominant in this experiment, is the loss asseciated with the voltage dropacress the arc itself. The forward dropot the spark gap was observed to jump between f() and 6) volts. The maximum output current is I amp for the presentconfiguration, limited by the output transformer.

The samples were analyzed on a dual column gas chromatograph equipped with an electron capture detector: Results from the analysis areshown in Fig. 5. The reduced data shows a clear trend with respect to energy. We would like to predict the amount of PFIB that is formed for higher energies, by using the data we collext on the test-stand. Initial data looks promis-

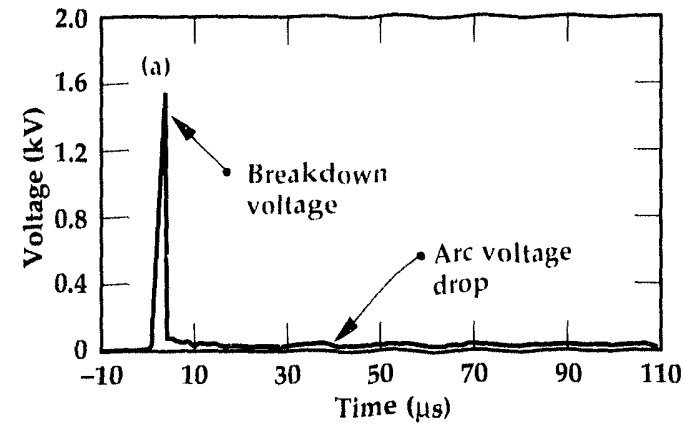

Figure 4. Typical data for (a) voltage and $(b)$ current waveforms.

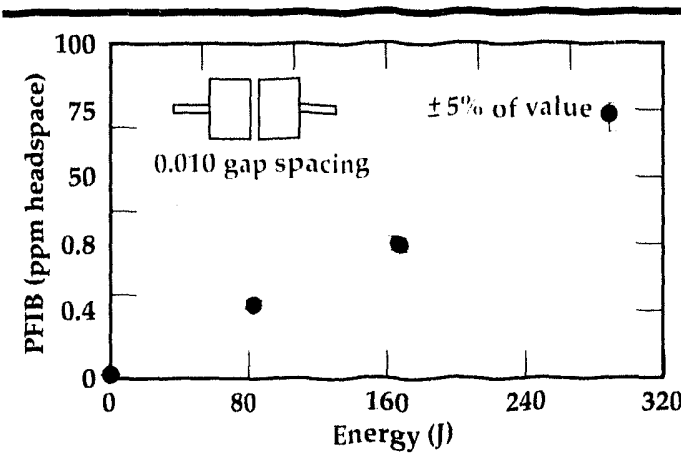

Figure 5. Typical data set for pulse breakdown-induced PFIB generation. The fluid sample was pulsed with a $30-k V$, $1+1 \mathrm{~s}$ pulse at a prf of $75 \mathrm{~Hz}$. This data was generated with brass electrodes and a 10.mil gap spacing in the dielectric test cup. The energy per pulse is $4 \mathrm{~mJ}$.

ing. The calculated fiedd for the breakdown voltage is much lower than what was expected based on the published fluid characteristics. Further investigation showed that the breakdown level is much higher at lower pref due to fluid recovery. Although this is no surprise, it is a key variable in the pulsed breakdown of these fluids.

\section{Superconducting SuperColliderTests}

We have been funded by the SSC to test for the amount of PFIB that is potentially produced in their LEB cavities. We have set up a working agreement with SSC to establish P'FIB generation data for LEB corities. Also, we are providing measurement capabilities for quantifying 
PFIB in samples they provide. The first sample generated by SSC was subjected to 60) $\mathrm{kV}$ for 20) hours of operation. An electrostatic model of the LEB cavity was generated using Ansoft's Maxwell $2 D^{7}$, and the maximum electric field in the fluid was calculated to be $83 \mathrm{kV} / \mathrm{cm}$. They reported that during the operation, there were no detectable breakdowns. The samples were analyzed, and no PFIB was measured above the $60 \mathrm{ppbv}$ detection limit.

\section{Future Work}

Our plans for the next fiscal year are focused on three key areas.

(1) Wearecurrently working to generate a comprehensive and complete data set for various arc-induced breakdown conditions for various fluids. The last year was dedicated to developing the needed test-stand and diagnostics as well as chemical and analytical techniques. Now that the testing facility is in place, we will fill in our data set and analyze the results for PFIB generation trends, with respect to parameters such as energy, power, and prf.

(2) In addition to the continued testing of the replacement fluids, we propose to test, in cooperation with $3 \mathrm{M}$, a fluid contamination detection system. The system uses a UV source (not specified) and detector to measure the transparency of the fluid. Initial tests have been conducted by $3 \mathrm{M}$, which show that the fluid's transmission changes by as much as $20 \%$ when the fluid is subjected to high thermal stress. We will test various detector configuration and breakdown parameters to decide if the detector can be used as a reliable means to signal the possibility of PFIB contamination in hostile working environments.

(3) The third area that has been identified is the refrigeration industry. In the majority of industrial refrigeration systems, the refrigcrant is circulated through the compressor motor, for cooling and lubrication. ${ }^{8}$ In large systems, the voltage level can exceed 1000 volts, leading to the occasional and often catastrophic electrical breakdown of the fluid. Our test-stand is capable of reproducing these breakdown conditions in the laboratory where a comprehensive analysis can be performed.

1. Statement by presidential l'ress Secretary Hizwater on the Phaseout of Ozone Depleting Substances, February $11,1992$.

2. P. Elmer-Dewitt, "How Do You Patcha Hole in the Sky That Could Be as Big as Alaska?," Timn' 139 (7), (Fobruary 17,1992).

3. A.K. Nai, "CFC Substitutes Might Be Toxic, Rat Study Finds," Woll Strect fommonl, July 2, 1991.

4. M. Weisskopf, "Study Finds CFCAlternatives More Damaging Than Believed," The Worh/ington l'ost, February 23, 1992.

5. ASTMStandard D 877-87, Dielectric Brakiturem Vollugeof linsuluting Liquids Llsing Disk Electrode's (1989).

6. I.C. Martin, Nanosecont Pulse Tedmiques, Atomic Weapons Research Establishment, United Kingdom Note t, 1970.

7. Maximill 2D Fich Simulator, Version 4.33, Ansoft Corporation.

8. Altheuse, Turnquist, and Bracciano, Mortem Retrig cration and Air Conditioning, The Gondheart-Willow Company, Inc., (South Holland, Illinois) 1988. 


\title{
Applying Statistical Electromagnetic Theory to Mode Stirred Chamber Measurements
}

\author{
Richard A. Zacharias and \\ Carlos A. Avalle \\ Defense Sciences Engineering Division \\ Electronics Engineering
}

We are developing measurement and analysis tools to assess microwave effects on electronic subsystems that operate in large metal cavities, such as avionics boxes in aircraft. The measurement tool is the mode stirred chamber (MSC), which is a metal-walled chamber, large relative to a wavelength, into which electromagnetic energy is injected. It usually contains a stirrer paddle to randomly change resonant mode patterns as a function of time. The analysis tools are based on statistical electromagnetics. This theory predicts that the microwave power measured at an arbitrary point (not near the walls) within an overmoded, randomly complex cavity is a Chisquared distribution with two degrees of freedom. This is a single-parameter distribution. Therefore, the mean power density measured at an arbitrary point in the cavity is sufficient to develop a complete statistical model of the power at any arbitrary interior point. By showing that a randomized aircraft equipment bay has sufficient $Q$ and ensemble variations to behave as such a random complex cavity, we have determined that the mean coupling measured at a point in the cavity would be sufficient to predict the microwave stress (statistical distribution of fields) to which an avionics box would be exposed over an ensemble of like aircraft (the fleet). A MSC could be used to generate the same distribution for testing avionics boxes uninstalled. This method could provide tremendous cost savings in testing. In FY-92, we developed a small, lowpower MSC and verified that its interior power distribution is indeed predicted by the theory. We also made measurements in two equipment bays of a Boeing 707 aircraft and verified that the power measured at various points in these cavities has the same distribution. The aircraft tests were funded by the NASA Langley Research Center and were conducted in collaboration with the U.S. Naval Surface Warfare Center, Dahlgren.

\section{Introduction}

Modern transportation systems and military systems are increasingly dependent on sophisticated electronic controls. At the same time, the potential for electromagnetic (EM) susceptibility of electronic systems is increasing for several reasons: modern integrated circuits with higher densities and speed are often more sensitive to EM transients; modern composite material structures may provide poorer EM shielding; the EM power in the environment is increasing as more users share the airwaves. Because of these factors, the need to ensure the survivability of electronic systems that may be exposed to high-power EM signals has become of great interest. Advisory regulation has recently been drafted for aircraft that would require testing and/or analysis to assure the EM hardness of installed flight critical and flight essential equipment. Similar safety assurance certification procedures may be imposed on other electronically controlled transportation systems of the future. The Department of Defense (DOD) is particularly interested in developing methods for assessing potential EM effects on military systems, since the normal environment these 


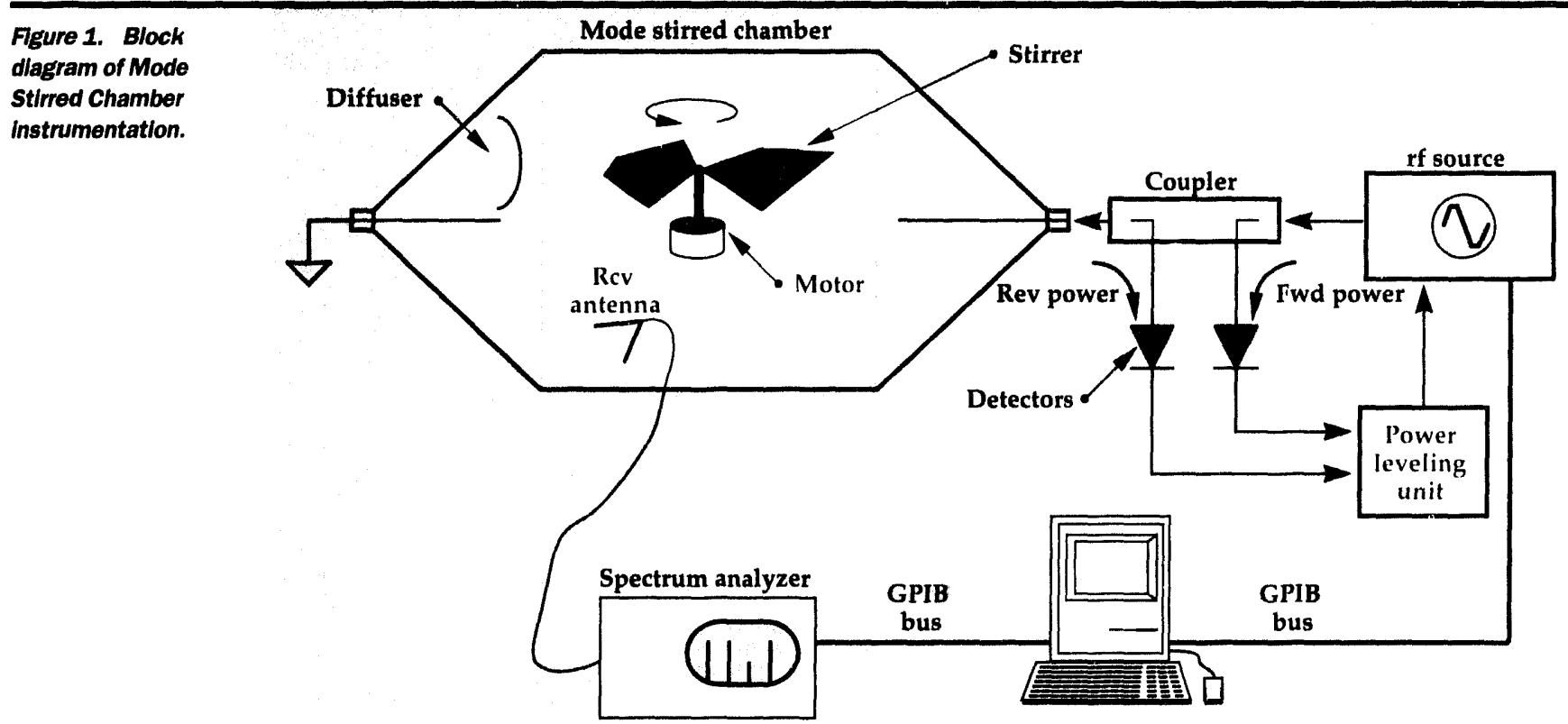

systems operate in is often quite severe (e.g., an aircraft carrier deck), and since these systems may be exposed to high-power signals intentionally transmitted by an adversary. The DOD also needs similar methods to assess the lethality of proposed EM weapons against candidate targets.

While full-system, full-threat testing may be the most thorough manner to determine susceptibility, it is often too expensive to be practical for large systems. Computer models alone have been unsuccessful in accurately predicting EM susceptibility, especially at high frequencies. At Lawrence Livermore National Laboratory (LLNL), we have developed economical assessment techniques based on measuring and comparing EM stress and strength.2 The power to a device or circuit (stress) is extrapolated from a low-power EM coupling measurement and is compared against the upset threshold (strength) of the device or circuit. A system model is used to relate device or circuit effects to system effects. This technique works well for small systems such as missiles and land mines, but for large systems, the number of measurements and analyses becomes large. In addition, as the system size becomes many wavelengths, the coupling as a function of frequency and angle also becomes extremely complex to the point that deterministic descriptions cannot be made. In this regime, new methods of testing and modeling must be developed. We believe that the mode stirred chamber (MSC) and statistical electromagnetics will provide a new method to make viable stress-vs-strength comparisons for subsystems, $3,4,5$

\section{Progress}

Our first major accomplishment was to develop a small, low-power MSC. The chamber was equipped with a power leveling circuit and with automated control and data acquisition instrumentation. Chamber performance was characterized. Our second major accomplishment was to measure and analyze the statistical distribution of microwave power in equipment bays of a fullsized transport aircraft. The measured distribution matched that measured in the MSC and that predicted by theory.

\section{MSC Development}

Our MSC was built from an existing transverse electromagnetic (TEM) cell. A TEM cell is designed tooperate single mode and produces a well-known field pattern usually used to calibrate sensors. Above its cutoff frequency, the TEM cell becomes increasingly overmoded. To promote more effective overmoding, we removed a section of the septum (center conductor), and added large reflective diffusers, to scatter the energy in random directions within the cell. A motor-spun stirrer paddle, large compared to the wavelength, randomizes the field pattern as a function of time. At frequencies greater than several times the cutoff $(f>40) \mathrm{MHz})$, the mode density is large, and the stirring produces random field patterns.

Figure 1 shows a block diagram of the MSC instrumentation. A low-power microwave source 
delivers the EM energy into the chamber. The if signal can be fed into the chamber through the usual TEM cell input port or by a separate horn antenna placed inside the chamber. A power leveling unit was developed to dynamically adjust the power to compensate for power reflected at the transmit antenna due to changes in the voltage standing wave ratio (VSWR) as the stirrer turns. We used a variety of sensors and antennas, and a spectrum analyzer to measure power at various points in the chamber. Fully automatic control and data acquisition were implemented with a personal computer.

\section{Boeing 707 Tests}

Tests were conducted at Davis Monthan Air Force Base in Tucson, Arizona. The experimental setup is shown in Fig. 2. The interior of the aircraft equipment bay under study was instrumented with two transmit and two receive antennas. Each pair consisted of a long wire and a horn antenna. The transmit antennas were driven by low-power microwave sources installed in an adjacent instrumentation van, and were oriented to avoid direct illumination of the receiving antennas. Spectrum analyzers were used to measure power at various points within the bays, while a motorized stirrer paddle randomly changed the mode pattern as a function of time. The stirrer motion simulated the random variations in the position of equipment in the bays throughout the fleet of aireraft. P'ortable computers were used for data acquisition and analysis. Power was measured at discrete frequencies for each of the four possible transmit and receive antenna combinations. The measurements were repeated for several antenna locations within the aircroft bays.

\section{Analysis and Results}

The time (or stirrer position) waveforms for both the MSC and aircraft data looked similar in that the received amplitude varied rapidly with excursions of 20 dB or more. The time data was statistically analyzed to generate probability density histograms of the power (in $\mathrm{dBm}$ ). These are shown in Fig. 3 ( $a$ and $\mathbf{b}$ ), for the aircraft and MSC, respectively, along with the theoretical probability density (dashed curves). The predicted density was derived from a two-degree-offeredom, Chisquared density using a variable transformation to convert to $\mathrm{dB}$. The aircraft and MSC data compare well to each other and to theory.



Figure 2. Block diagram of instrumentation for microwave power statistical distribution measurements made at Davis Monthan Airbase on a Boeing 707.

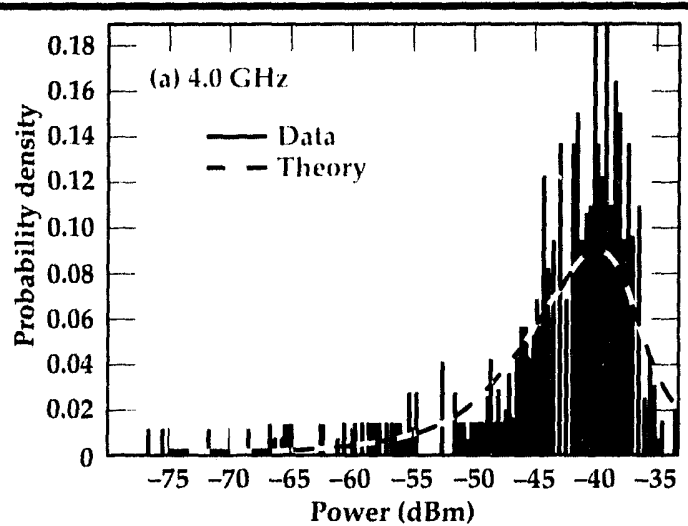

Figure 3.

Probability density of measured power in (a) the mode stirred chamber and (b) the equipment bay of a Boeing 707.

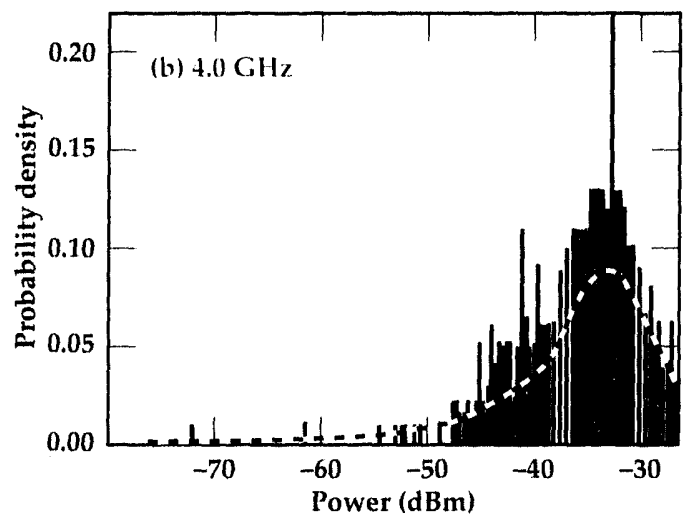




\section{Future Work}

Four issues must be resolved before certified, quantitative subsystem assessments can be made in MSC's:

1. MSC tests must be shown to be repeatable, predictable, and rigorous. This is necessary for the technique to be accepted by government regulators and industry.

2. The power distribution in the MSC must match that found in the system cavity. This ensures that the subsystem sees the same EM power environment as if it were installed.

3. Coherence length must be understood and the effects of structures near the subsystem taken into account. A structure installed in the cavity will interact with a subsystem if their separation is within a coherence length. Therefore, structures within this length will need to be simulated in the MSC for accurate results.

4. The transfer function describing coupling to devices in the subsystem must be shown to be separable into a product of coupling from outside the system cavity to its interior, and coupling from the cavity interior to the devices within the subsystem. An example of a non-separable case is when the major coupling into the subsystem is through a waveguide that exits the cavity. In this case, the random field environment in the cavity is immaterial, and MSC tests would not provide accurate results.

In FY-92, we developed a small MSC facility and instrumentation. We made measurements in the MSC and in a commercial aircraft that showed that the power distributions matched each other and the theory. In FY-93, we are planning experiments to resolve the remaining issues. We will use statistical EM theory to make predictions of the coupling as a function of frequency, onto simple wire antennas in the MSC, and compare those predictions against measurements. This will help to demonstrate that MSC tests can be rigorous and predictable. Since the prediction will be based on the correlation of the field components picked up by wire segments of the antenna, this will also serve to validate our understanding of coherence length. Separability will be demonstrated experimentally in our anechoic chamber and MSC using simple metal boxes representing an airframe and an avionics box. Once shown for a simple case, the measurements will be repeated with various cable and transmission line connections to the avionics box to establish the cases where separability does and does not hold.

The end product of this study will be a set of theoretically and experimentally validated EM susceptibility assessment tools that would allow accurate EM effects testing of subsystems at high frequency, while avoiding expensive high-power full-system tests.

1. A. Pesta and N. Chesser, Depurtment of Defense Methodology Guidelines for High Pouerer Microwane (HPM) Susciptibility Ass'ssmints, Office of the Secretary of Defense, HPM Methodology Panel Report, Draft (1989).

2. R. Mensing, R.J. King, and H.S. Cabayan, A Method for Estimating the Susceptibility of Electronic Systems to HPM, Lawrence Livermore National Laboratory, Livermore, California, UCID-21430 (1988).

3. M. Crawford and G. Koepke, Design, Evnluation, and User of a Rererberntion Clanmber for Performing Electromaringtic Susceptibility/Nulnerability Mensumements, NBS Technical Note 1092 (1986).

4. R. Price, H. T. Daris, R. H. Bonn, E. P. Wenaas, R. Achenbach, V. Gieri, R. Thomas, J. Alcala, J. Hanson, W. Haynes, C. McCrea, C. Montano, R.Peterson, B. Trautlein, and R. Umber, Determinntion of the Statistical Distrilution of Electrommgnetic Field Amplitude's in Complex Conities, Jaycor Report No. 88JAL129 (1988)

5. T. Lehman, The' Statistics of Electromagnetic Fichts in Conities aith Complex Shopes, Phillips Laboratory Interaction Note (1993). 


\section{Magnetically Delayed LowPressure Gas Discharge Switching}

\author{
Stephen E. Sampayan, \\ Hugh C. Kirbie, and \\ Anthony N. Payne \\ Laser Engineering Division \\ Electronics Engineering
}

\author{
Eugene Lauer and \\ Donald Prosnitz \\ Advanced Applications Program \\ Laser Programs
}

We have investigated the properties of a magnetically delayed, low-pressure gas discharge switch. We performed measurements of the closure and recovery properties of the switch; performed quantitative erosion measurements; and observed the onset of $\mathrm{x}$ ray production in order to compare switch properties with and without delay. Further, we performed qualitative optical measurements of transition line spectra to correlate our electrical recovery measurements with plasma deionization.

\section{Introduction}

Fast-closure-rate, high-voltage ( $>100 \mathrm{kV})$, highcurrent $(>10 \mathrm{kA})$, high-repetition-rate $(>1 \mathrm{kHz})$ switching has remained a major area of research in the pulsed power field.1,2,3 Solid-state switching has generally been limited to several tens of kilovolts; high-pressure gas discharge switching is limited to repetition rates below $1 \mathrm{kHz}$; vacuum switching is generally a slow closure process; and magnetic switching requires extremely precise voltage and reset state control to minimize jitter.

Low-pressure gas discharge switches have shown promise as a fast-closing, high-repetitionrate device such that if sufficiently fast closure times can be achieved, single-stage power conditioning chains would become feasible. 4,5

The primary difficulty with this switch, however, is anode electrode damage during closure initiation, resulting in short lifetimes. Once triggered, electrons emitted from the cathode plasma can form a pinched beam and deposit significant enough localized energy to vaporize anode material. Inserting a series delay element, which inhibits the application of full voltage and current until such time that the discharge plasma has filled the gap, minimizes this effect. It is this version of the low-pressure switch that we are presently studying.

\section{Progress}

Our magnetically delayed low-pressure switch (MDLPS) test-stand was built primarily to support the long-pulse, relativistic klystron (RK) and free electron laser (FEL) work at Lawrence Livermore National Laboratory (LLNL). ${ }^{6}$ In this application, a closing switch initiates a pulse, which is delivered to an induction accelerator cell. 7 The induction cell accelerates an injected electron beam to a sufficient energy suitable for the RK or FEL.

\section{Apparatus}

The MDLPS test-stand (Fig. 1) consists of a single water-filled, $12-\Omega, 70-n$ s Blumlein from the advanced test accelerator at LLNL. The Blumlein is attached to a liquid load and charged from a single dual-resonant transformer. The transformer is powered by two charged capacitor banks discharged through separate thyratrons, diode isolated and fired sequentially to produce two charging pulses. A trigger pulser initiates a single closure event at the peak of the first charging pulse; the second, variable timing, charging pulse is allowed to ring to zero and is used as a test pulse to verify gap recovery.

The low-pressure gas gap consists of an anodecathode electrode pair separated a sufficient dis- 
Figure 1. Switch test-stand used to study magnetically delayed switch prop erties.

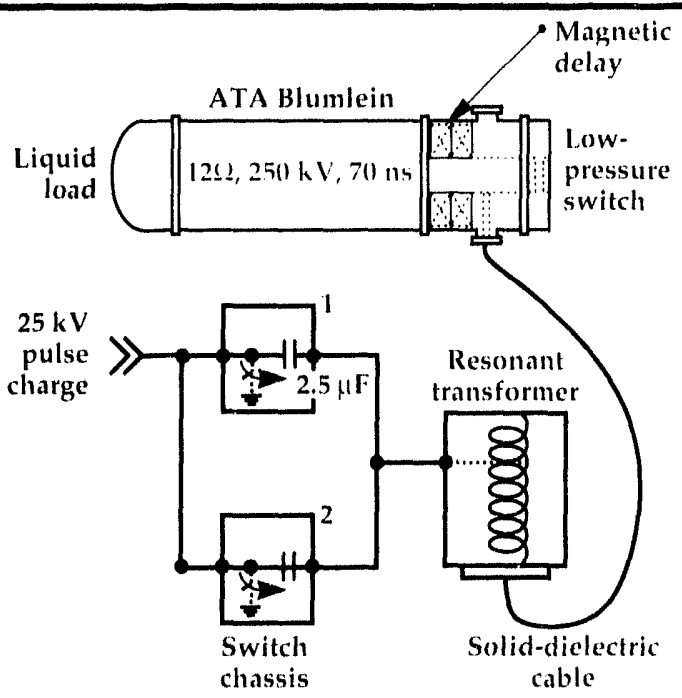

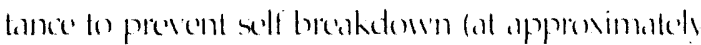

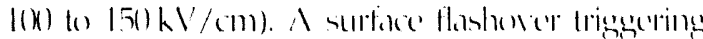
cterice, embedded within the cathede, initiollen the

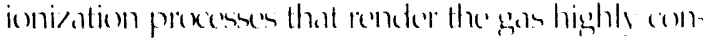

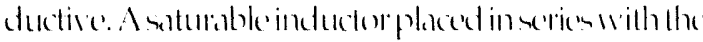

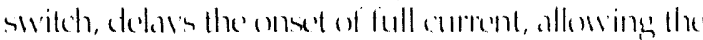

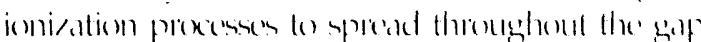

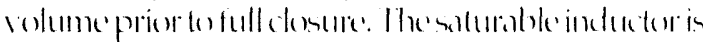

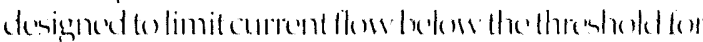

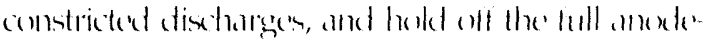

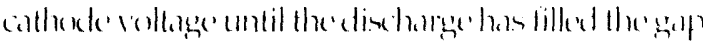
rolume:

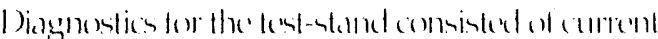

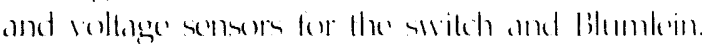

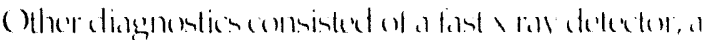

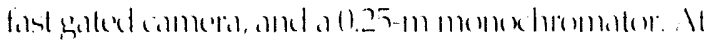

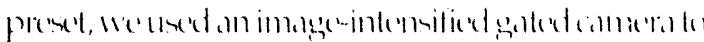

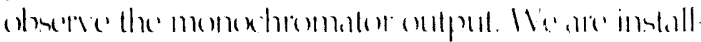

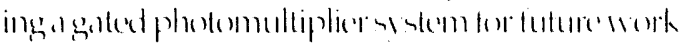

\section{Experiments}

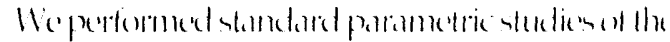

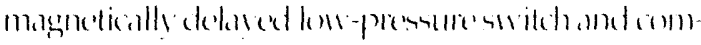

Figure 2. Measured closure results with and without delay.

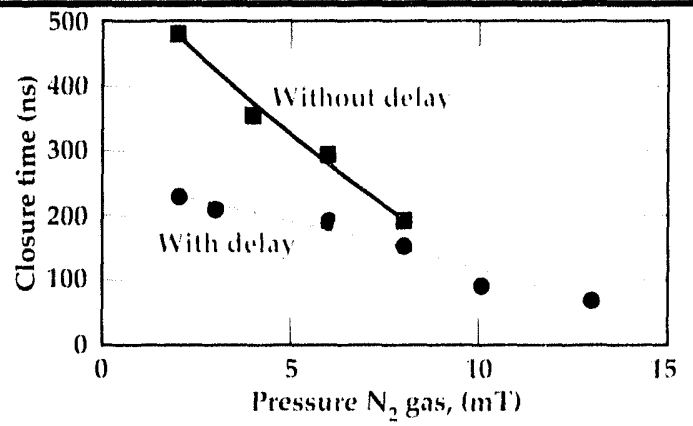

pared the pertimmancereith and without the sestura-

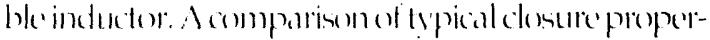
lise is shown in Fig. 2, and of Iypical recosers propertics in Fig. 3. For these data, the gap spacing was 1 am, the gis was nitrogen, and the andexterathaxterollagerwase)

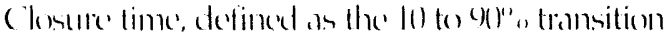

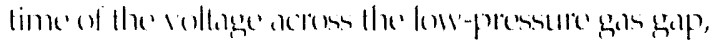

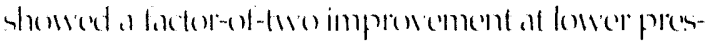

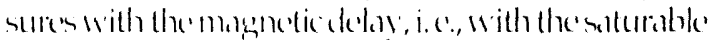

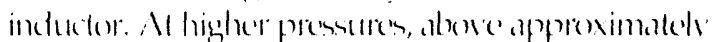

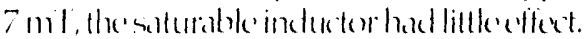

Recosers lime with the seriens atumble indecter

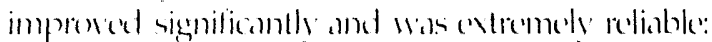

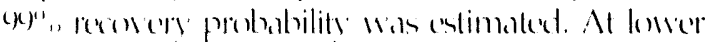

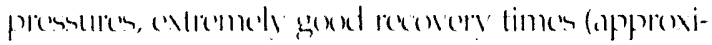
mated.

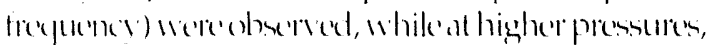

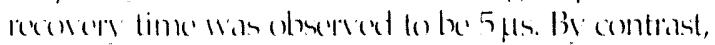
recosers probabilits without the series soturable in-

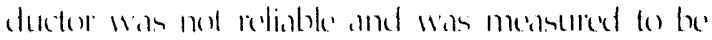

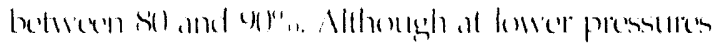

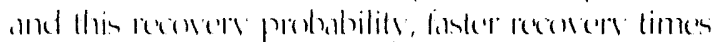

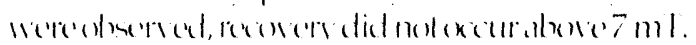

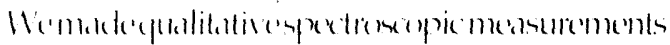

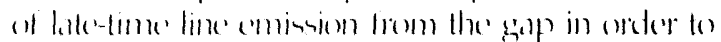

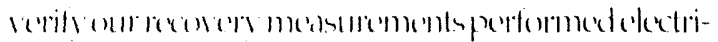

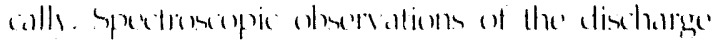

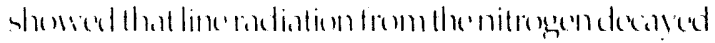

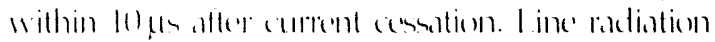

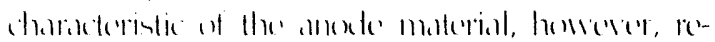

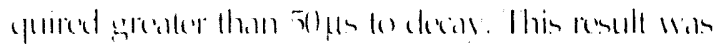

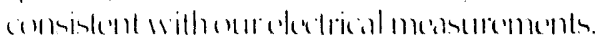

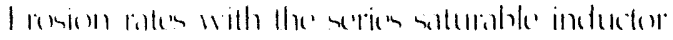

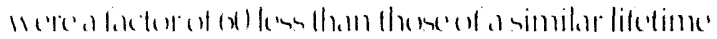

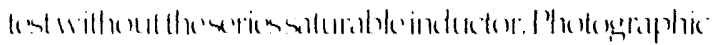

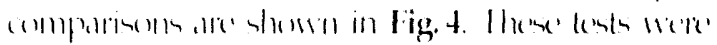

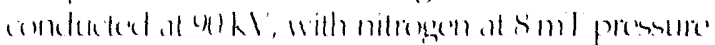

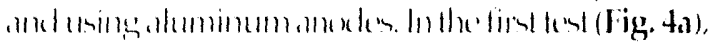

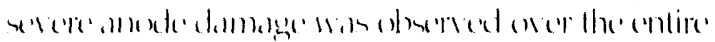

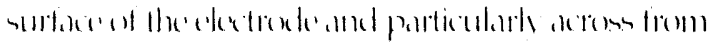

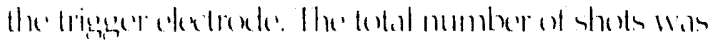

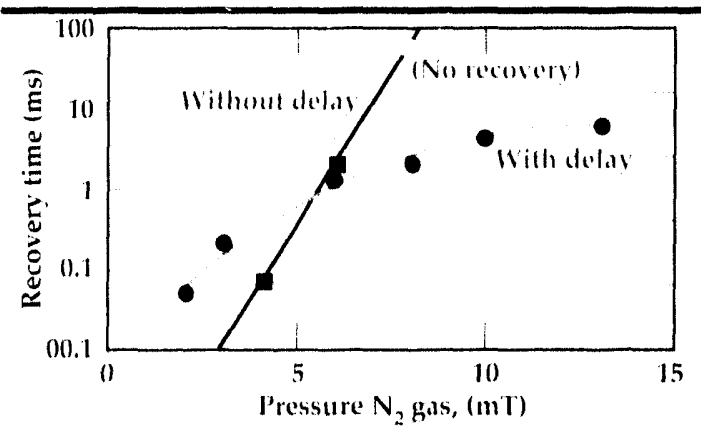

Figure 3. Electrically measured recovery results. 
approximately $16,(x)$. In the second test (Fig. 4b), a iess pronounced indentation resulted from the test, with minimal damage hasing eccurred throughout the anode surface. The total number of shots during this latter test was approximately $f(x),(x)$ ().

We performed $x$ ray measurements (Fig. 5) to understand the time evolution of electronemission from the cathexte of the low-presstore switch. Our relative measurements of the integrated $x$ lay output during switch closure showed an order-ot-magnitude decrease with the series saturable inductor. Further, we observect the most intense $x$ ray output from the low' pressureswitch during the initiation or 'trigger delay' periend without the series saturable indecter, and after the closine process had begun with the series siturable inductor:

Wealso measured the variation of the $x$ ray output from the gap at various gals pressures. From this measurement, we observed the rayouput decrease by about 30 "w when the gas pressure was increased from 1 toremt

\section{Modeling}

We developed a onedimensional model fer the closure regime of the low-pressire switch. In this moxtel, the motions of ionsand electronsaremodeled by cold fluid equations that include collision iomization and space tharge effects. The mextel expantions are parameteriad in terms of gas type (iomisation) coefficient) and pressure; swe itch gap length and oresssectional arear and the initial electrom density prot duced by the trigger pulse. This moxtel permits as to follow the space-time exolution of the electric fied and the ion and elextron current densitien in the gops, as well as the total switch current and terminal roltage during switele dosture.

We have implemented the moxtel in a generallpurpose network and system simulation coxte. This
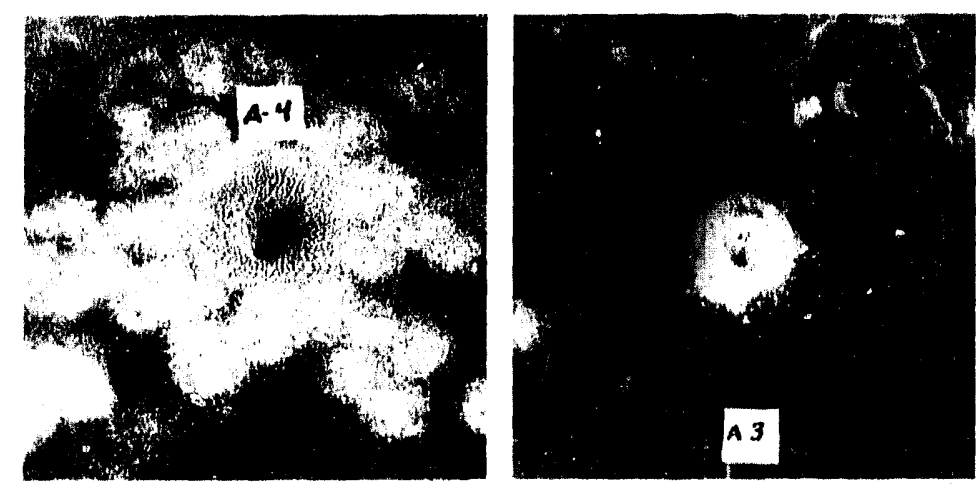

implementation permits the construction of a detailed system simulation moxtel of the test-stand that includes the charging circuit, Blumlein, magnetic switch, and load. Wo use a magnetic switch moxtel that includes mate-dependent l(x)p-widening of the hysteresis lexpe, hysteretic losses, minor loxps. and hysteresis effects." l'resently, we are validating the low-pressure switch and magnetic switch moxtels against experimental data. ( nnce validated, the complete system moxtel should permit us to study the

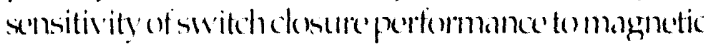
come parametersand to low-pressureswitch parametors stach as clectrente spaxing and initial elextron density, and thereby provide us with a tex)l for makingswitch designt traterotis.

\section{Future Work}

Wo hale demomstrated that the use of a series solurable indecter placed in series with a lowpressure gas spark gap greatly enhances performance from our medsurements, we understand this improsed performance to be primarily due to minimising ancetematerial saporizalion during the initial clesure of the gap. Without the series solturable inductor, a ray emission occurs
Figure 4. Comparison of electrode erosion (a) without and (b) with magnetic delay.
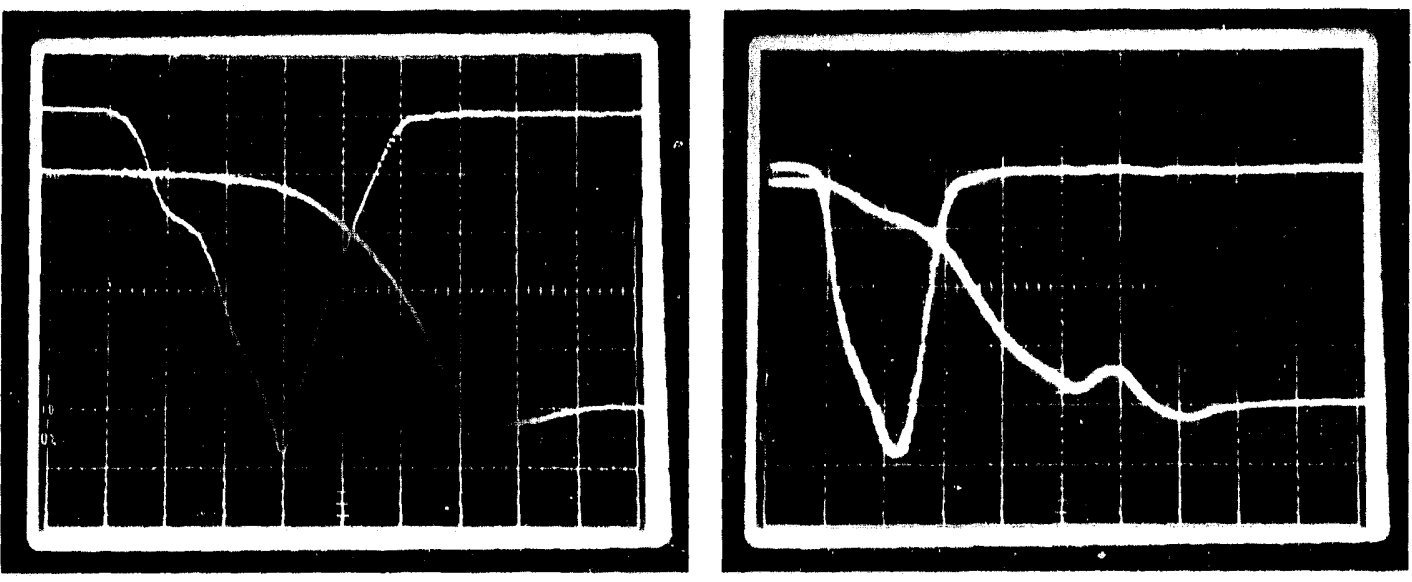

Figure 5. Measured $x$ ray pulse (top curve) and closure (bottom curve) of the low-pressure switch (a) without magnetic delay $(0.5$ $V / d i v$.) and (b) with magnetic delay $(0.1$ V/div.). Horizontal scale is $100 \mathrm{~ns} / \mathrm{div}$. 
from the point of triggering until the initial collapse of the gap impedance. The energy deposition into the anode is large as determined by the integrated $x$ ray intensity. With the series saturable inductor, energy deposition into the anode is initiated at the instant the collapse of the gap impedance occurs. The net effect is lower energy deposition into the anode.

From our data, we conclude that with our present triggering method, this switch is capable of operating as either a low-repetition-rate final output switch or, berause of the slower closure times at low pressure, as a high-repetition-rate initial commutation switch, i.e., in the initial stages of the power conditioning chain. Although the present triggering device appears adequate, it is difficult to couple a significant portion of the trigger electrical energy into the low-pressure gas. In future work, we will install newly developed, simple, ferroelectric electron emitters as a triggering device. ${ }^{4}$ Current densities from 0.1 to $1 \mathrm{kA} / \mathrm{cm}^{2}$ have been extracted from such an emitter for several hundred nanoseconds. Such a device should allow better coupling of the trigger electrical energy to the low-pressure gas. We would therefore expect much faster closure times even at lower pressures.

Our spectral observations indicate that recosery is primarily inhibited by anode vapor remaining ionized in the gap. It is well established that recombination times for metal vapor exceed those of gasses by at least an order of magnitude. Thus, to enhance recovery, we will investigate the use of anode materials with low heat of vaporization, in order to minimize the accumulation of anode material vapor in the gap.

1. Ci. Schacfer, M. Kristiansen, and A. Guenther, Gols

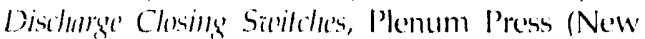
York, New York), 199().

2. H.C. Kirbic, (i.). Caporaso, M.A. Newton, and S. Yu, "Livolution of High-Repetition-Rate Induction Accelerators Through Advancements in Switching," 1992 Limer Accillerillor Coml. Prow, 595 (1992).

3. R.A. Dougal, (.D.). Volakakis, and M.I). Abdalla, "Magnetically Delayed Vacuum Switching," Pres: oth ITLE Pulsid Power Comf., 21 (1987).

4. E.J. Latuer and D.L. Birx, "Low L'ressure Spark

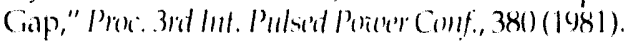

5. E.J. Latuer and D.L. Birx, "Tests of a Low Pressure Switch Protected by a Saturable Inductor," $\| I: L$

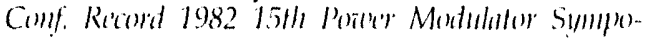
siluiin, 47 (1982).

6. T.L. Houck and G.A. Westenskow, "Status of the Choppertron Experiments," 1992 Line'ur Accelertotor Collf. Pros, +498(1992).

7. S. Humphries, Principhes of Chargert Particle Aciol rertion, John Wiley and Sons, Inc. (New York, New York), 28.3ff (1986)

8. A.N. P'ayne, "Modeling Magnetic Pulse Compressors," Comf. Re'cont logl Particle Acceleralor Cont. $3(1) 91(1491)$.

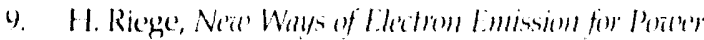

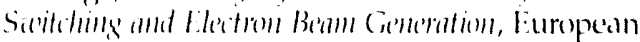
Organization for Nuclear Rescorch, Report CIRN-PS $89 / 42(A R)(1489)$. 

